\title{
Effects of cloud condensation nuclei and ice nucleating particles on precipitation processes and supercooled liquid in mixed-phase orographic clouds
}

\author{
Jiwen Fan ${ }^{1}$, L. Ruby Leung ${ }^{1}$, Daniel Rosenfeld ${ }^{2}$, and Paul J. DeMott ${ }^{3}$ \\ ${ }^{1}$ Atmospheric Science \& Global Change Division, Pacific Northwest National Laboratory, Richland, WA 99352, USA \\ ${ }^{2}$ Institute of Earth Sciences, The Hebrew University of Jerusalem, Jerusalem, 91904, Israel \\ ${ }^{3}$ Department of Atmospheric Science, Colorado State University, Fort Collins, CO 80523, USA
}

Correspondence to: Jiwen Fan (jiwen.fan@pnnl.gov)

Received: 26 August 2016 - Published in Atmos. Chem. Phys. Discuss.: 31 August 2016

Revised: 6 December 2016 - Accepted: 21 December 2016 - Published: 23 January 2017

\begin{abstract}
How orographic mixed-phase clouds respond to the change in cloud condensation nuclei $(\mathrm{CCN})$ and ice nucleating particles (INPs) are highly uncertain. The main snow production mechanism in warm and cold mixed-phase orographic clouds (referred to as WMOCs and CMOCs, respectively, distinguished here as those having cloud tops warmer and colder than $-20^{\circ} \mathrm{C}$ ) could be very different. We quantify the CCN and INP impacts on supercooled water content, cloud phases, and precipitation for a WMOC case and a CMOC case, with sensitivity tests using the same CCN and INP concentrations between the WMOC and CMOC cases. It was found that deposition plays a more important role than riming for forming snow in the CMOC case, while the role of riming is dominant in the WMOC case. As expected, adding CCN suppresses precipitation, especially in WMOCs and low INPs. However, this reverses strongly for $\mathrm{CCN}$ of $1000 \mathrm{~cm}^{-3}$ and larger. We found a new mechanism through which CCN can invigorate mixed-phase clouds over the Sierra Nevada and drastically intensify snow precipitation when CCN concentrations are high $\left(1000 \mathrm{~cm}^{-3}\right.$ or higher). In this situation, more widespread shallow clouds with a greater amount of cloud water form in the Central Valley and foothills west of the mountain range. The increased latent heat release associated with the formation of these clouds strengthens the local transport of moisture to the windward slope, invigorating mixed-phase clouds over the mountains, and thereby producing higher amounts of snow precipitation. Under all CCN conditions, increasing the INPs leads to decreased riming and mixed-phase fraction in
\end{abstract}

the CMOC as a result of liquid-limited conditions, but has the opposite effects in the WMOC as a result of ice-limited conditions. However, precipitation in both cases is increased by increasing INPs due to an increase in deposition for the CMOC but enhanced riming and deposition in the WMOC. Increasing the INPs dramatically reduces supercooled water content and increases the cloud glaciation temperature, while increasing $\mathrm{CCN}$ has the opposite effect with much smaller significance.

\section{Introduction}

Snowpack in the Sierra Nevada is California's largest source of fresh water. Understanding the factors contributing to snow precipitation over the mountains has important implications for predicting the hydrology and local climate of the western US. This has motivated a series of CalWater field campaigns carried out since 2009 to improve understanding of processes influencing precipitation and water supply in California (Ralph et al., 2016). Closely linked to precipitation is the distribution of cloud liquid and ice phases, which may be influenced by supercooled liquid commonly occurring in orographic clouds over the Sierra Nevada (Rosenfeld et al., 2013). In addition to precipitation, cloud radiative forcing and cloud feedback in the climate system are also highly dependent on cloud phases because of the very different radiative effect of liquid and ice particles. Hence, understanding the key processes and factors impacting cloud phases is 
critical, but our lack of understanding and ability to model supercooled liquid and cloud phases is limiting skillful predictions on weather and climate timescales.

Many factors, such as large-scale dynamics, solar heating, and aerosol particles, can impact cloud properties and precipitation over the Sierra Nevada (Shen et al., 2010; Rosenfeld et al., 2008). Atmospheric rivers (ARs) are one of the primary large-scale dynamical features that bring large amounts of water vapor from tropics to the US west coast, and they can create extreme rainfall and floods (Bao et al., 2006; Ralph et al., 2011; Neiman et al., 2010). Aerosols can modify cloud microphysical processes and potentially alter the location, intensity, and type of precipitation (Tao et al., 2012) by acting as cloud condensation nuclei $(\mathrm{CCN})$ or ice nucleating particles (INPs). In California, anthropogenic aerosols from the densely populated coastal plains and the Central Valley may be incorporated into the frontal air mass before orographic ascent and influence precipitation in the Sierra Nevada (Rosenfeld and Givati, 2006). Long-range transported aerosols (mainly dust particles) have also been found to have a potential influence on clouds and precipitation in the winter and spring seasons (Uno et al., 2009; Ault et al., 2011; Creamean et al., 2013).

Aerosol impacts on clouds not only depend on aerosol properties such as number, size, and composition but also dynamics and thermodynamics. Rosenfeld et al. (2014) showed significantly different supercooled-water (SCW) and precipitation processes in two contrasting cloud cases with air masses containing maritime and continental aerosols, respectively. Many studies have shown that $\mathrm{CCN}$ can reduce warm rain precipitation from orographic clouds by reducing the efficiency of cloud droplet conversion into raindrops (e.g., Lynn et al., 2007; Rosenfeld and Givati, 2006; Jirak and Cotton, 2006), and they can also reduce snowfall precipitation due to reduced riming efficiency (Lowenthal et al., 2011; Rosenfeld et al., 2008). However, some recent studies show a possibility of increased precipitation by $\mathrm{CCN}$ in orographic mixed-phase clouds (Fan et al., 2014; Xiao et al., 2015). Other studies have shown that CCN may not have a significant effect on the total precipitation but rather they shift precipitation from the windward to leeward slope, a so-called "spillover effect" (Lynn et al., 2007; Saleeby et al., 2011, 2013). By acting as INPs, aerosols can enhance ice growth processes such as deposition and riming and thereby significantly increase snow precipitation (Fan et al., 2014). Both observational and modeling studies have shown that longrange transported dust and biological particles can enhance orographic precipitation in California by serving as INPs (Ault et al., 2011; Creamean et al., 2013, 2014, 2015; Fan et al., 2014).

In addition to precipitation, aerosols may have significant impacts on cloud phase and SCW in the mixed-phase clouds, which directly change cloud radiative forcing and Earth's energy balance. Modeling studies have shown that $\mathrm{CCN}$ tend to increase SCW via the processes such as suppressed warm rain and/or reduced riming efficiency (Khain et al., 2009; Ilotoviz et al., 2016; Saleeby et al., 2013). A recent observational study corroborated that increasing $\mathrm{CCN}$ decreases the cloud glaciation temperature and thus increases the abundance of the mixed-phase regime (Zipori et al., 2015). With abundant INPs such as dust particles, clouds glaciate at a much warmer temperature (Rosenfeld et al., 2011; Zipori et al., 2015). It was found that commonly occurring supercooled water in the clouds near the coastal regions of the western US is associated with low-CCN and limited-INP conditions (Rosenfeld et al., 2013). Models generally have difficulties simulating SCW and cloud phases. For example, recent evaluation of the Community Atmosphere Model version 5 (CAM5) with satellite data showed that the model has insufficient liquid cloud and excessive ice cloud from the midlatitudes to the polar regions, and liquid deficit bias maximizes over the Southern Ocean where supercooled water is prevalent (Kay et al., 2016). For cloud model simulations with cloud-resolving models, ice nucleation parameterizations often need to be modified in order to produce the mixedphase clouds in the Arctic region (Fan et al., 2009; Fridlind et al., 2007). Considering that many microphysical processes are sensitive to aerosol types (CCN or INP), temperature, and/or supersaturation (e.g., deposition growth), aerosol impacts on cloud phase and SCW can be complicated depending on cloud dynamics and thermodynamics. Our current understanding of cloud microphysical processes impacting SCW and cloud phase in different meteorological environments is poor. Therefore, it is important to conduct processlevel studies to improve our understanding.

Fan et al. (2014) conducted a study for two mixed-phase orographic cloud cases with different cloud temperatures and showed different significance of the CCN and INP impacts on precipitation between the two cases, with much more significant impacts of INPs. The two cases are 15-16 February 2011 (FEB16) and 1-2 March 2011 (MAR02). FEB16 has a cloud top temperature as cold as $-32{ }^{\circ} \mathrm{C}$, while the cloud top temperature of MAR02 is generally warmer than $-20^{\circ} \mathrm{C}$. The temperature difference at the same altitude between the two cases is about $6-10^{\circ} \mathrm{C}$. For these reasons, we will herein refer to them as cold mixed-phase orographic clouds (CMOCs) and warm mixed-phase orographic clouds (WMOCs), respectively. The main snow-forming mechanism in warm and cold mixed-phase orographic clouds could be very different and could lead to different precipitation responses to changes in CCN and INPs, which has not been studied so far. Following Fan et al. (2014), this study aims to (1) understand the dominant ice growth processes in these two mixed-phase cloud systems and (2) quantify the response of precipitation to the changes in CCN and INPs over a wide range from extremely low to extremely high concentrations, and (3) examine CCN and INP impacts on SCW and cloud phases. The same Weather Research and Forecasting (WRF) model with the spectral-bin microphysics (SBM) as used in Fan et al. (2014) is employed. Ice nucleation is parameter- 
ized in dependence on mineral dust-biological particle concentrations on the basis of observational evidence. To provide a better process-level understanding and to better realize our science goals, the simulation resolution is further increased to $1 \mathrm{~km}$ and the simulations are driven with the $2 \mathrm{~km}$ resolution baseline simulation from Fan et al. (2014).

\section{Model description and simulation design}

\subsection{Model description}

As in Fan et al. (2014), simulations are performed using WRF version 3.1.1 developed at the National Center for Atmospheric Research (NCAR) (Skamarock et al., 2008) coupled with a SBM model (Khain et al., 2009; Fan et al., 2012). The SBM model is a fast version of the full SBM model described by Khain et al. (2004), in which ice crystal and snow (aggregates) in the full SBM model are calculated based on one size distribution with separation at $150 \mu \mathrm{m}$. Ice crystal and snow are referred to as low-density ice. Graupel and hail in the full SBM model are grouped as high-density ice, represented with one size distribution without separation. More details about the SBM model that we used in this study can be found in Fan et al. (2014).

As discussed in Fan et al. (2014), hereafter referred to as FAN2014, the ice nucleation parameterizations in the SBM model used for this study were modified. A new ice nucleation parameterization of DeMott et al. (2015) (cited as DeMott et al., 2013 in FAN2014 before the parameterization was published) was incorporated in the SBM model to investigate the impacts of dust as INPs. The parameterization connects nucleated ice particle concentration under a certain atmospheric condition with aerosol particle number concentration with a diameter larger than $0.5 \mu \mathrm{m}\left(n_{a>0.5} \mu \mathrm{m}\right.$ in Eq. 2 of DeMott et al., 2015). In FAN2014, the aerosol particles that are connected with the DeMott et al. (2015) parameterization are referred to as "dust-bio" (from single-particle mass spectral composition measurements) and are based on observations from the Passive Cavity Aerosol Spectrometer Probe (PCASP) for particles with a diameter larger than $0.5 \mu \mathrm{m}$ from clear-sky aircraft data. Note that the actual INP number concentration in the DeMott et al. (2015) parameterization includes an exponential temperature dependence that acts on aerosol concentration and that the exponent on aerosol concentration is 1.25 . Therefore, in this paper we vary the constant $n_{a>0.5 \mu \mathrm{m}}$ over a range of relevant conditions to investigate the impacts of varied INP concentration. It should also be noted that the parameterization is designed and implemented as immersion freezing, that is, a pre-existing liquid particle (droplet or drop) is consumed for each formed ice crystal determined by the parameterization (at the same time, an ice nucleus is removed from the INP category). An added feature of the implementation is that when immersion freezing occurs freezing starts from the largest drops first, followed by the smaller ones over the size spectrum of water drops. This implementation yielded the majority of large ice particles as observed by aircraft measurements (FAN2014). Adding deposition-condensation freezing produces a large amount of small ice particles, which is not consistent with observations. Therefore, deposition-condensation freezing is not included, as discussed in FAN2014. The assumption that the largest drops freeze first also acknowledges the expectation that the largest droplets should have a higher probability of containing an INP active at a given temperature. For contact freezing, we adopt the implementation of Muhlbauer and Lohmann (2009) for the parameterizations described in Cotton et al. (1986) and Young (1974) to connect with INPs. The contribution from the contact freezing with this parameterization is negligible. As described in FAN2014, dust-bio particle concentration (i.e., IN proxy) is a single prognostic variable separated from CCN. For the simulation of the observed case in FAN2014, dust-bio concentration is initiated with the concentration of clear-sky aerosol particles with a diameter larger than $0.5 \mu \mathrm{m}$ in the dust layer. Over-nucleation is prevented by applying an upper limit of ice particle concentration.

\subsection{Design of numerical experiments}

In FAN2014, simulations were done for the two nested domains with a horizontal grid spacing of 10 and $2 \mathrm{~km}$. To focus on the orographic clouds over the Sierra Nevada and provide a better process-level understanding, we conduct new simulations using a smaller domain of $300 \mathrm{~km} \times 280 \mathrm{~km}$ with a grid spacing of $1 \mathrm{~km}$ (the yellow box in Fig. 1a) nested within the $2 \mathrm{~km}$ grid spacing domain of FAN2014 (the blue box). The domain grid points are $301 \times 281$ horizontally with 51 vertical levels. The initial and lateral boundary conditions are produced from the baseline simulations of the $2 \mathrm{~km}$ grid spacing in FAN2014 that were validated by various observational data. The lateral boundary data are updated every $3 \mathrm{~h}$. The rapid radiative transfer model for global circulation models (RRTMG) shortwave and long-wave radiation schemes are used to account for aerosol-cloud-radiation interactions based on the droplet effective radius calculated by SBM.

CCN in the model are represented by a spectrum with 33 size bins with prognostic $\mathrm{CCN}$ number concentrations for each bin. As stated above, dust-bio particle number concentration serves as a proxy for INP concentration in this region. For the purpose of this study, we conduct sensitivity tests by varying CCN and INP proxy (i.e., dust-bio particle) concentrations over a wide range from extremely low to extremely high concentrations, as shown in Table 1 . The initial CCN concentrations for the sensitivity simulations are set to be $30,100,300,1000$, and $3000 \mathrm{~cm}^{-3}$ (referred to as CCN30, CCN100, CCN300, CCN1000, and CCN3000, respectively). For each $\mathrm{CCN}$ condition, simulations are conducted with the initial dust-bio particle concentration of 0.1 , 
(a)

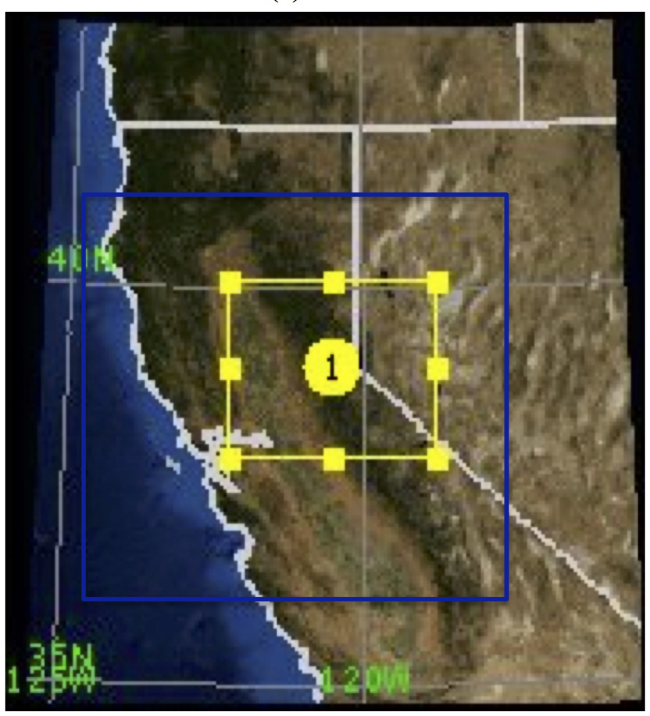

(b)

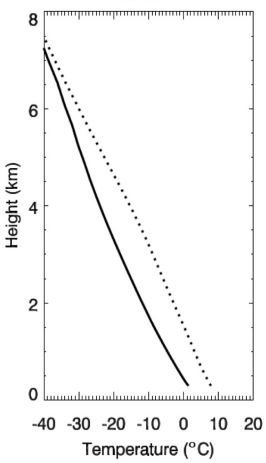

(c)

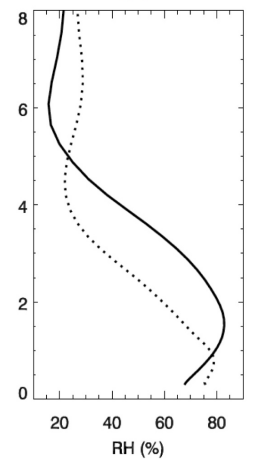

(d)

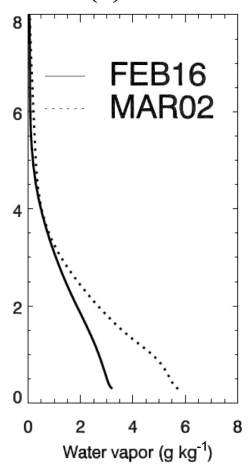

Figure 1. (a) The simulation domain (yellow box) and the vertical profiles of (b) the temperature, (c) RH, and (d) water vapor for the CMOC (FEB16) and WMOC (MAR02). (b)-(d) Domain mean values during the model simulation time periods. The blue box in (a) denotes the domain of $2 \mathrm{~km}$ resolution simulations done in FAN2014.

1,10 , and $100 \mathrm{~cm}^{-3}$, respectively, referred to as INO.1, IN1, IN10, and IN100. Note that the conversion of $\mathrm{cm}^{-3}$ dust-bio to INPs per liter is shown in Fig. 10 of DeMott et al. (2015). We also include a table (Table 2) in this study to clearly show the corresponding INP concentrations under different dustbio particle concentration at a certain temperature. For example, $0.1 \mathrm{~cm}^{-3}$ dust-bio means $\sim 0.02 \mathrm{~L}^{-1}$ nucleated ice particles at $-20^{\circ} \mathrm{C}$ and $\sim 0.2 \mathrm{~L}^{-1}$ at $-25^{\circ} \mathrm{C}$. These numbers of INPs are akin to the number concentrations of INPs found in the natural marine boundary layer (DeMott et al., 2016). In contrast, $10 \mathrm{~cm}^{-3}$ dust-bio, common within some transported dust layers, means $\sim 5 \mathrm{~L}^{-1}$ nucleated ice particles at $-20^{\circ} \mathrm{C}$ and $\sim 50 \mathrm{~L}^{-1}$ at $-25^{\circ} \mathrm{C}$ (Table 2). The vertical profiles of CCN and INP proxy concentrations at the initial time are uniform below $6 \mathrm{~km}$ since observations do not show significant vertical variations as discussed in FAN2014. Simulations are conducted for both cases and start at 12:00 UTC and run for $12 \mathrm{~h}$ since the majority of the convective orographic clouds occur during this period. Note that the observed CCN (dust-bio) concentrations for the CMOC and WMOC cases are around $30(2)$ and $120(4) \mathrm{cm}^{-3}$, respectively.

As described earlier, the CMOC case on FEB16 has cloudtop temperatures of about $-32{ }^{\circ} \mathrm{C}$, which are about $10^{\circ}$ colder than the WMOC case on MAR02, and has higher relative humidity $(\mathrm{RH})$ due to the lower temperature, although the water vapor mixing ratio is much smaller (Fig. 1b-d). The temperatures of cloud bases over the mountain slope are about $0^{\circ} \mathrm{C}$ for the CMOC and about $6^{\circ} \mathrm{C}$ for the WMOC. Both cases are under the influence of both atmospheric rivers that provide ample water vapor supply and the long-range transported dust-bio. However, we note that the lower-level
Table 1. Model simulations that are run for different CCN and INP proxy aerosol concentrations. Please note that INP proxy aerosol concentrations denote dust-bio particle number concentrations with particle size $>0.5 \mu \mathrm{m}$ for use in the parameterization of DeMott et al. (2015), as described in FAN2014.

\begin{tabular}{rrrrrr}
\hline & \multicolumn{5}{c}{ INP proxy aerosol } \\
& & concentrations & $\left(\mathrm{cm}^{-3}\right)$ \\
& 0.1 & 1 & 10 & 100 \\
\hline & 30 & $\mathrm{X}$ & $\mathrm{X}$ & $\mathrm{X}$ & $\mathrm{X}$ \\
$\mathrm{CCN}\left(\mathrm{cm}^{-3}\right)$ & 100 & $\mathrm{X}$ & $\mathrm{X}$ & $\mathrm{X}$ & $\mathrm{X}$ \\
& 300 & $\mathrm{X}$ & $\mathrm{X}$ & $\mathrm{X}$ & $\mathrm{X}$ \\
& 1000 & $\mathrm{X}$ & $\mathrm{X}$ & $\mathrm{X}$ & $\mathrm{X}$ \\
& 3000 & $\mathrm{X}$ & $\mathrm{X}$ & $\mathrm{X}$ & $\mathrm{X}$ \\
\hline
\end{tabular}

wind directions in the two cases are different, with prevailing westerly and northwesterly winds on FEB06 and southerly and southwesterly winds on MAR02. Therefore, the two mixed-phase cloud cases have contrasting thermodynamics and dynamics.

\section{Results}

\subsection{CMOC - FEB16}

\subsubsection{Precipitation and microphysical processes}

Figure $2 \mathrm{a}$ shows the accumulated surface precipitation averaged over the domain for the CMOC case (FEB16). Increasing the INPs generally enhance the domain-averaged 
(a)

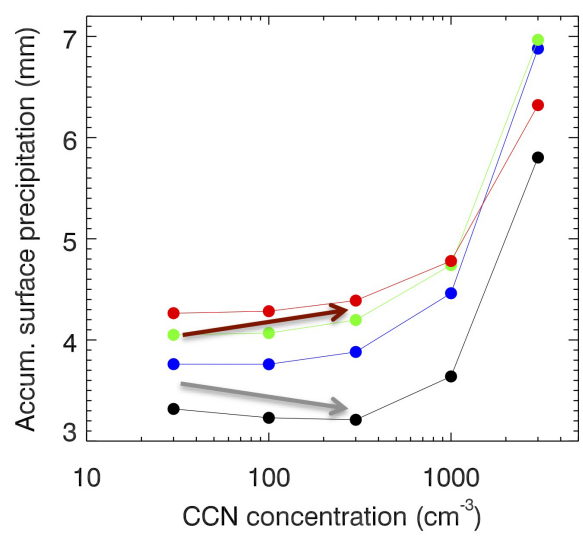

(b)

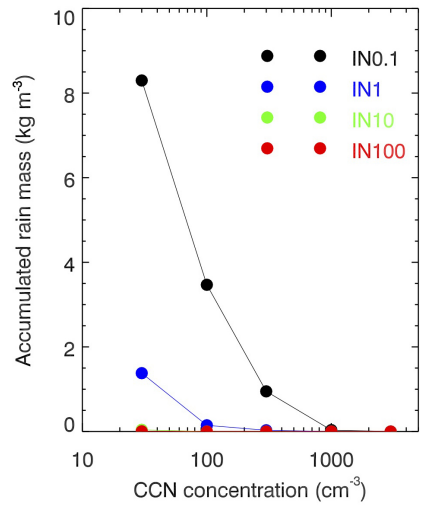

(c)

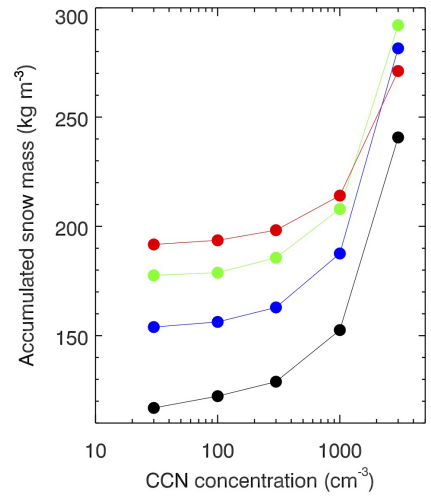

Figure 2. (a) The domain-mean accumulated surface precipitation, and the accumulated (b) rain and (c) snow mass concentrations at the lowest model level ( $\sim 40 \mathrm{~m}$ above the surface) during the simulation time period for the CMOC case. All domain-mean calculations exclude the lateral boundary grid points in this study. The grey arrow indicates the decrease trend under low INP proxy concentrations, and the magenta arrow is for the increase trend under high INP proxy concentrations.

Table 2. INP concentrations $\left(\mathrm{L}^{-1}\right)$ calculated based on DeMott et al. (2015) under different INP proxy aerosol concentrations (i.e., dust-bio particles in this study) at the various temperatures.

\begin{tabular}{lrrrrrrr}
\hline & \multicolumn{7}{c}{ Temperature $\left({ }^{\circ} \mathrm{C}\right)$} \\
\cline { 2 - 8 } Dust/bio $\left(\mathrm{cm}^{-3}\right)$ & -5 & -10 & -15 & -20 & -25 & -30 & -35 \\
\hline 0 & 0.00 & 0.00 & 0.00 & 0.02 & 0.15 & 1.52 & 15.19 \\
1 & 0.00 & 0.00 & 0.03 & 0.27 & 2.71 & 27.08 & 270.05 \\
10 & 0.00 & 0.05 & 0.49 & 4.84 & 48.27 & 481.47 & 4802.27 \\
100 & 0.09 & 0.87 & 8.63 & 86.06 & 858.40 & 8561.88 & 85397.75 \\
\hline
\end{tabular}

precipitation except at extremely high $\mathrm{CCN}$ concentration (i.e., $3000 \mathrm{~cm}^{-3}$ ) as a result of increased snow precipitation (Fig. 2c). The sensitivity to INP concentration gets much smaller when INP proxy aerosol concentrations are $10 \mathrm{~cm}^{-3}$ and larger. Under the low-INP condition where the liquid regime is dominant, the precipitation is first suppressed as $\mathrm{CCN}$ increase up to a polluted condition of $1000 \mathrm{~cm}^{-3}$ (grey arrow). This behavior is similar to the $\mathrm{CCN}$ effects on shallow warm clouds. As INPs are further increased and mixedphase clouds are increased, the decreased trend of precipitation with the increase in $\mathrm{CCN}$ is changed to a monotonic increasing trend, as shown by the brown arrow in Fig. 2a. The most significant feature of Fig. 2a is the sharp increase in surface precipitation from CCN of 1000 to $3000 \mathrm{~cm}^{-3}$, even at the lowest-INP condition. This is inconsistent with our previous understanding for deep mixed-phase clouds that precipitation should be significantly suppressed under the extremely polluted conditions because droplets get too small to grow efficiently and the riming also becomes very inefficient (Fan et al., 2007; Li et al., 2008). From Fig. $2 b$ and c, which show the liquid and snow mass concentrations near the surface (i.e., at the lowest model level of $\sim 40 \mathrm{~m}$ above the ground), respectively, we see that (1) snow dominates the precipitation for the CMOC case and the ratio of warm rain to total precipitation is very small and (2) the dramatically enhanced snow explains the sharp increase in precipitation from $\mathrm{CCN}$ of 1000 to $3000 \mathrm{~cm}^{-3}$. Note that increasing $\mathrm{CCN}$ enhances snow precipitation under any INP condition (Fig. 2c), and warm rain is totally shut off when $\mathrm{CCN}$ are $1000 \mathrm{~cm}^{-3}$ or larger for the IN0.1 condition (Fig. 2b) due to the much smaller size of droplets.

By looking at the in-cloud microphysical properties, as shown in Fig. 3, increasing $\mathrm{CCN}$ enhances snow number concentration and mass mixing ratio $\left(N_{\mathrm{s}}\right.$ and $Q_{\mathrm{s}}$, respectively). We especially see a large increase in snow mass from CCN1000 to CCN3000. Cloud ice number concentration and mass mixing ratio $\left(N_{i}\right.$ and $Q_{i}$, respectively) are also increased. Note that ice and snow are represented with a single size spectrum and a threshold size of $150 \mu \mathrm{m}$ in radius is used to separate them. As discussed in Sect. 2, the major ice nucleation occurs through the immersion freezing of DeMott et al. (2015) and with a specification that the largest droplets freeze first when ice nucleation occurs. Therefore, most of the newly formed ice particles should be large and should fall into the snow bins. Therefore, $N_{\mathrm{s}}$ and $Q_{\mathrm{s}}$ contribute more significantly to ice number and mass increase 

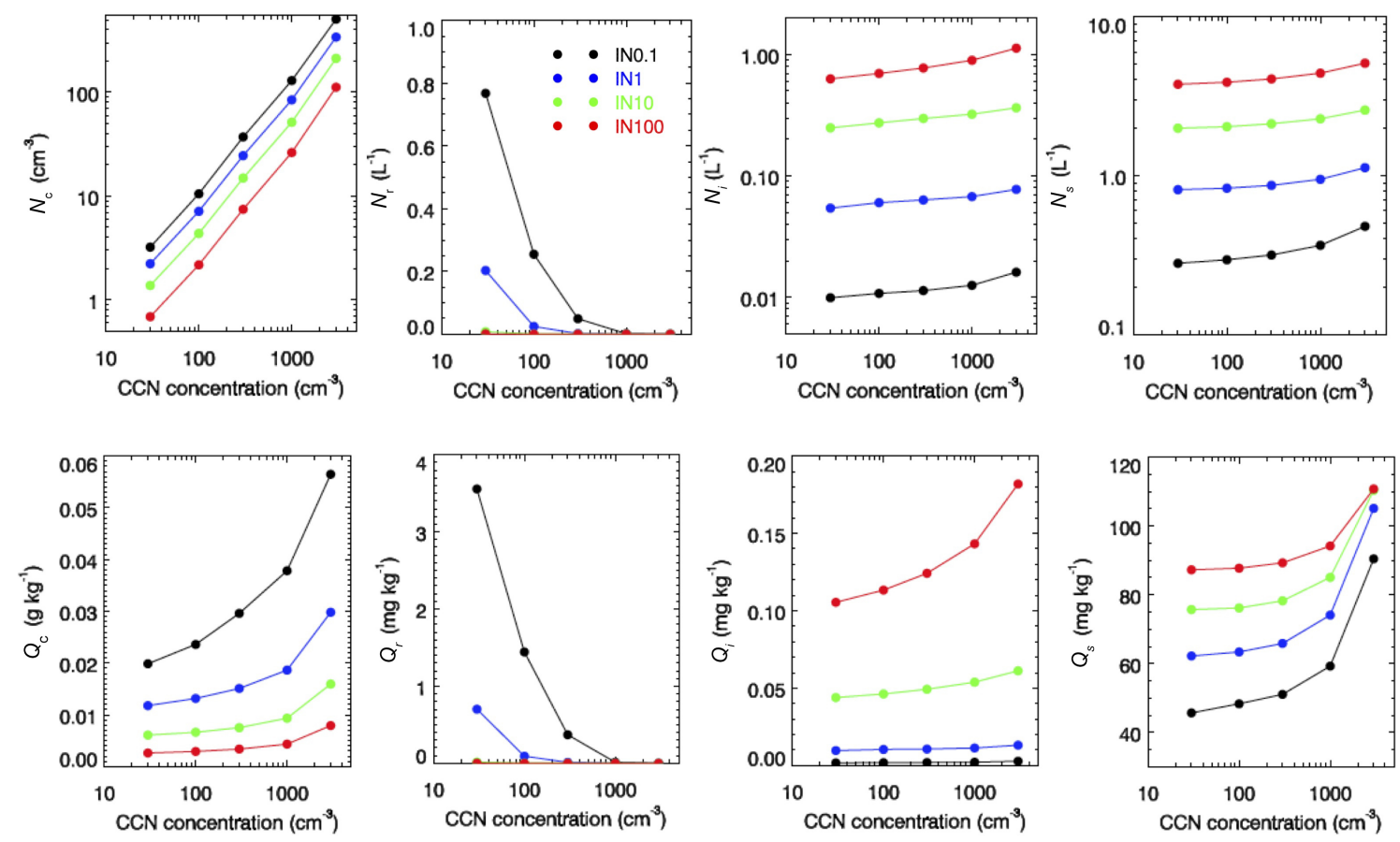

Figure 3. The number concentrations (top row) and mass mixing ratios (bottom row) of droplets (first column), rain (second column), cloud ice (third column), and snow (fourth column) for the CMOC. The data are averaged over the grid points over the domain by excluding the lateral boundary grid points below the $7 \mathrm{~km}$ altitude and over the simulation time by excluding the first $2 \mathrm{~h}$.

with the increase in $\mathrm{CCN}$ than do $N_{i}$ and $Q_{i}$. As CCN increase, not only the cloud droplet number concentration $\left(N_{\mathrm{c}}\right)$ is increased but also the cloud mass mixing ratio $\left(Q_{\mathrm{c}}\right)$. The large increase in $Q_{\mathrm{c}}$ when $\mathrm{CCN}$ are high, which corresponds to the large increase in $Q_{\mathrm{s}}$, will be scrutinized a little later. The decrease in raindrop number concentration and mass mixing ratio $\left(N_{\mathrm{r}}\right.$ and $Q_{\mathrm{r}}$, respectively) is very sharp and warm rain becomes negligible when INP proxy aerosol concentrations are $1 \mathrm{~cm}^{-3}$ or larger (Fig. 3).

From the process rates of the major microphysical processes shown in Fig. 4, we see that the increase in $Q_{\mathrm{c}}$ with the increase in $\mathrm{CCN}$ and the decrease in $Q_{\mathrm{c}}$ with the increase in INPs are well explained by the condensation rate (Fig. 4a), although the changes in evaporation have the same trends as well. As shown in Fig. 4c and e, deposition is a more significant process than riming except in the case of very low INPs (IN0.1) in this CMOC case. Increasing CCN enhances deposition but only enhances riming when $\mathrm{CCN}$ are high. The sharp increase in deposition and riming rates from CCN1000 to CCN3000 explains the sharp increase in snow with a major contribution from deposition. How deposition and riming are enhanced so significantly in this case will be elucidated in Sect. 3.1.2.

At very low INP concentrations (IN0.1), the riming rate is similar to the deposition rate in this CMOC case (Fig. 4c and e). As the INPs increase, the contribution of riming is reduced significantly because of the reduction of supercooled droplets resulting from increased ice particles in the mixedphase zone. Thus, the riming process is liquid-limited in this CMOC case. As a result of increased ice particles, deposition is enhanced significantly, and it becomes 3-4 times larger than riming in IN10. In the observed condition (i.e., $\mathrm{CCN}$ are between 30 and $300 \mathrm{~cm}^{-3}$ and INP proxies range between 1 and $10 \mathrm{~cm}^{-3}$ ), both deposition and riming contribute to the snow growth, but deposition is the major player. When INP concentrations are extremely high (IN100), clouds glaciate very fast and liquid droplets that are available for riming are limited; thus, their contribution is negligible (red line in Fig. 4e).

The Wegener-Bergeron-Findeisen (WBF) processes refer to ice depositional growth at the expense of liquid through evaporation in mixed-phase clouds. Therefore, the mixedphase cloud regime where vapor pressure falls between the saturation vapor pressure over water and ice is defined as the WBF regime. As CCN increase, the WBF processes get stronger, as shown in Fig. 5a and b. The ratio of evaporation through WBF to the total evaporation is larger than 0.92 in all simulations (Fig. 5a), meaning that drop evaporation in this CMOC case occurs predominantly in the WBF regime. Generally only $50-70 \%$ of deposition occurs in the WBF regime even when INP concentrations are in a range (IN0.1 to IN1) that is typical for this region in winter (Fig. 5b); thus, a significant portion of deposition occurs outside of the WBF regime, and the portion increases as INPs increase. There- 
(a) Condensation

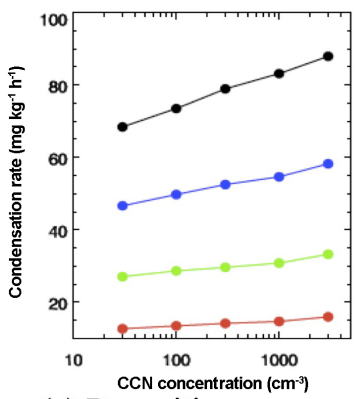

(c) Deposition

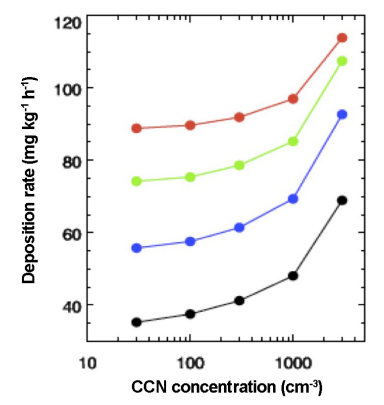

(e) Riming

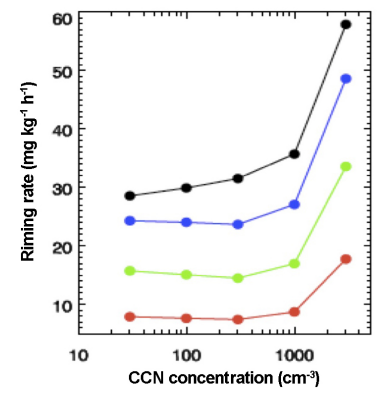

Figure 4. The microphysical process rates of (a) condensation, (b) evaporation, (c) deposition, (d) sublimation, and (e) riming for the CMOC. The model outputs for the process rates are every $6 \mathrm{~min}$, and the data shown in the plots were processed in the same way as Fig. 3.

fore, increasing the INPs generally reduce the WBF regime because of the reduced liquid due to enhanced depositional growth. In this CMOC case, the ratio of riming that occurs in the WBF regime to the total riming is small (generally around $0.2-0.4$ in Fig. 5c), meaning that riming mainly occurs outside of the WBF regimes under any $\mathrm{CCN}$ and INP conditions. The ratio is increased by $\mathrm{CCN}$ but generally decreased by INPs as a result of the increase or decrease of the liquid regime, respectively (Fig. 5c).

We see that all major microphysical processes (condensation-evaporation, deposition-sublimation, and riming) are highly sensitive to INPs, while generally having much lower sensitivity to $\mathrm{CCN}$ when $\mathrm{CCN}$ are below $1000 \mathrm{~cm}^{-3}$. The sensitivity of all the major microphysical processes to $\mathrm{CCN}$ becomes much more significant when
$\mathrm{CCN}$ are $1000 \mathrm{~cm}^{-3}$ and larger (Fig. 4), associated with significant changes in dynamics and thermodynamics and will be discussed in detail below.

\subsubsection{Mechanism of enhanced snow precipitation by highly elevated $\mathrm{CCN}$ concentrations}

Since the results of significantly enhanced precipitation from CCN1000 to CCN3000 are unusual, aside from verifying the use of identical initial and boundary meteorological conditions in all the experiments to eliminate simulation differences arising from inadvertent factors, we also conducted sensitivity tests by restoring the ice nucleation mechanisms to the default parameterizations (i.e., Meyers et al., 1992 for condensation and/or deposition and Bigg (1953) for immersing freezing) in the SBM but this yielded a similar conclusion. Consequently, the significantly increased snow precipitation associated with elevated CCN concentrations is not the result of the particular ice-forming parameterization or the implementation approach of the parameterization.

Since the precipitation enhancement begins at 14:00 UTC, which is a couple of hours into the simulations, we focus on the time period of 14:00-16:00 UTC and use the simulations of different $\mathrm{CCN}$ concentrations for the IN1 case to examine the mechanism. By taking a close look at ice nucleation (using model outputs every $6 \mathrm{~min}$ ), we find that the total nucleated ice particle number concentration increases as $\mathrm{CCN}$ increase and there is a large jump from $\mathrm{CCN} 1000$ to CCN3000 (Fig. 6a). The increase is caused by more cloudy points where ice nucleation (i.e., immersion freezing) occurs (Fig. 6b) and the enhanced nucleation rate (i.e., the nucleated ice particles per liter of air volume within $1 \mathrm{~h}$ ) in the lower altitudes (Fig. 6c). Considering that the major ice formation mechanism in this study is immersion freezing, which requires the existence of drops for primary nucleation of ice, there is much more supercooled liquid cloud area and/or volume available for nucleation in the lower altitudes as CCN increase (Fig. 6e). As shown in Fig. 6d, the increase in cloud water $\left(Q_{\mathrm{c}}\right)$ that is supercooled, since the warmest cloud temperature is below $0^{\circ} \mathrm{C}$ in this case, is very significant, with a big jump from CCN1000 to CCN3000, corresponding to the large increase in snow precipitation. From CCN1000 to CCN3000, the increase in the supercooled liquid area is especially drastic (Fig. 6e).

What causes the drastic increase in $Q_{\mathrm{c}}$ and a more widespread supercooled liquid cloud regime that is available for ice nucleation? We know that the increased drop surface area with the increased $\mathrm{CCN}$ can increase condensation, but it cannot explain such a drastic increase in the condensation rate averaged over the entire domain, as shown in Fig. 6f. We find that over the domain the updraft area (i.e., grid points with $w>1 \mathrm{~m} \mathrm{~s}^{-1}$ ) is increased significantly with $\mathrm{CCN}$, with a jump from CCN1000 to CCN3000 as well (Fig. 7a), but the averaged updraft velocity does not change significantly (Fig. 7b). This suggests that much more widespread con- 
(a)

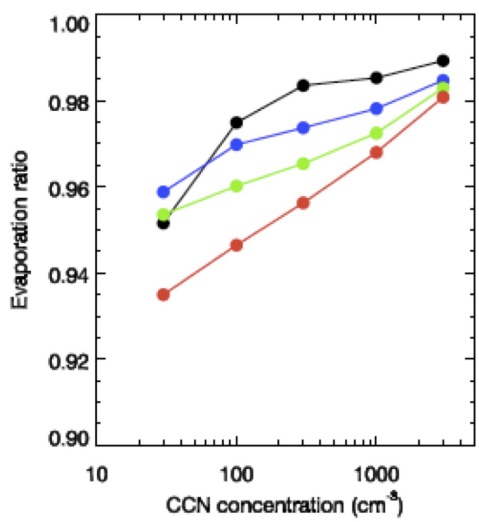

(b)

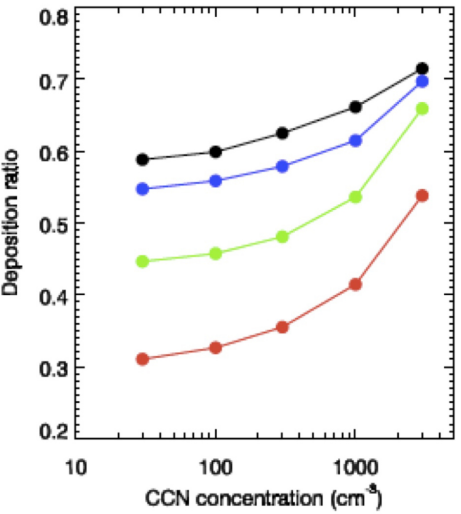

(c)

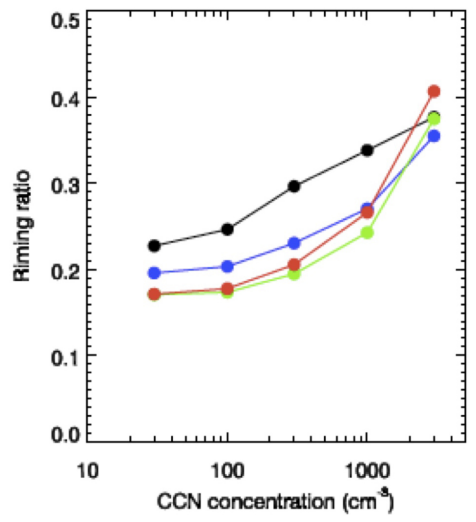

Figure 5. (a) The ratio of evaporation occurring in the WBF regime (defined as the grid points where the WBF processes occur) to the total evaporation for the CMOC. (b) and (c) are the same as (a), except for deposition and riming, respectively. Data were processed in the same way as Fig. 3. Lines and symbols follow Fig. 3.

(a)

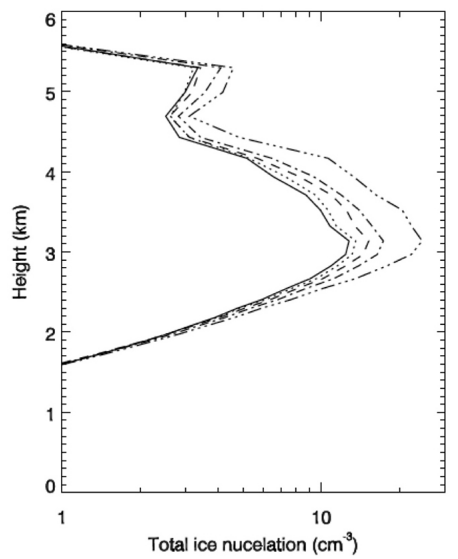

(d)

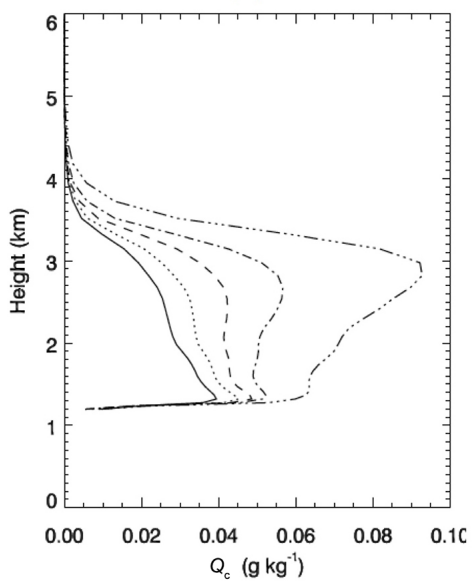

(b)

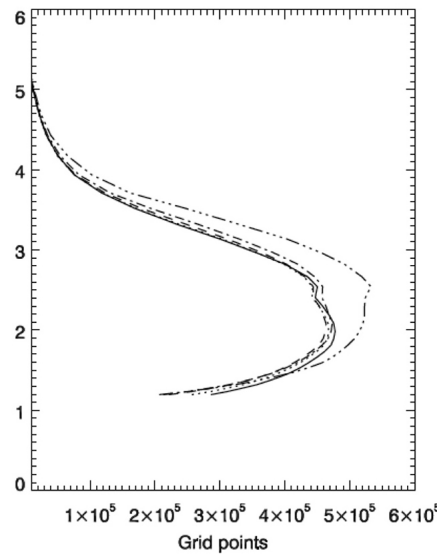

(e)

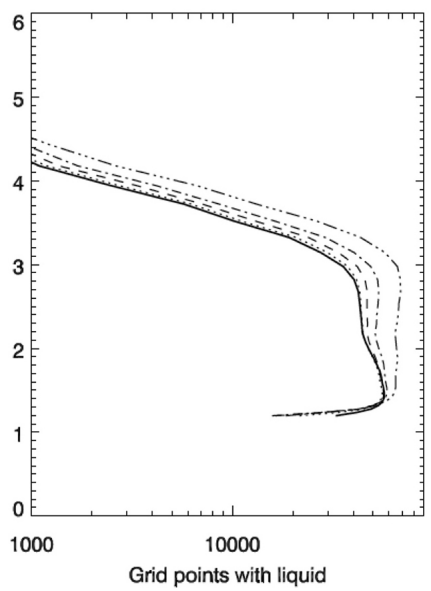

(c)

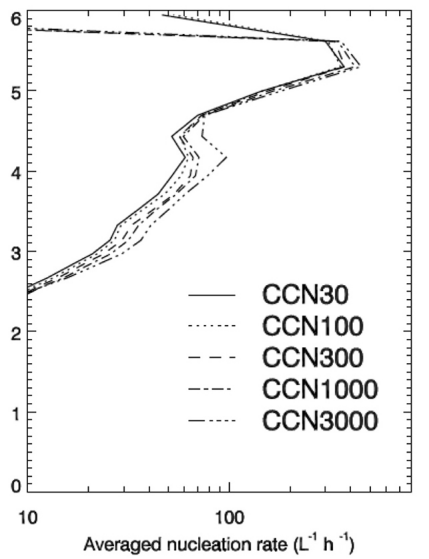

(f)

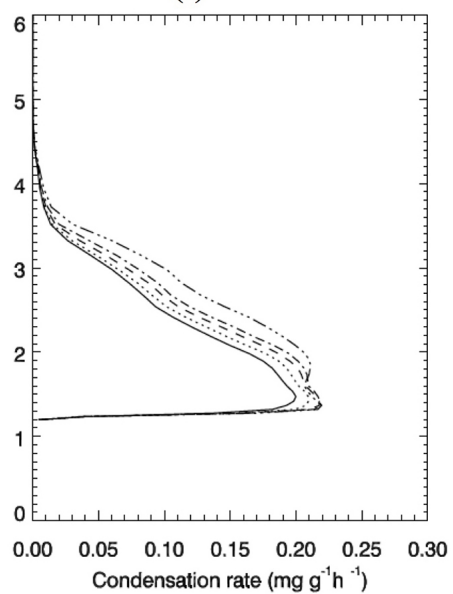

Figure 6. Vertical profiles of (a) total nucleated ice particles, (b) the total grid points where ice nucleation occurs, (c) the ice nucleation rate averaged over the total ice nucleation grid points, (d) domain-mean cloud water content $\left(Q_{\mathrm{c}}\right)$, (e) the total grid points that have liquid (i.e., the liquid water mixing ratio is larger than $10^{-5} \mathrm{~kg} \mathrm{~kg}^{-1}$ ), and (f) the domain-mean condensate rate during 14:00-16:00 UTC for the CMOC 
(a)

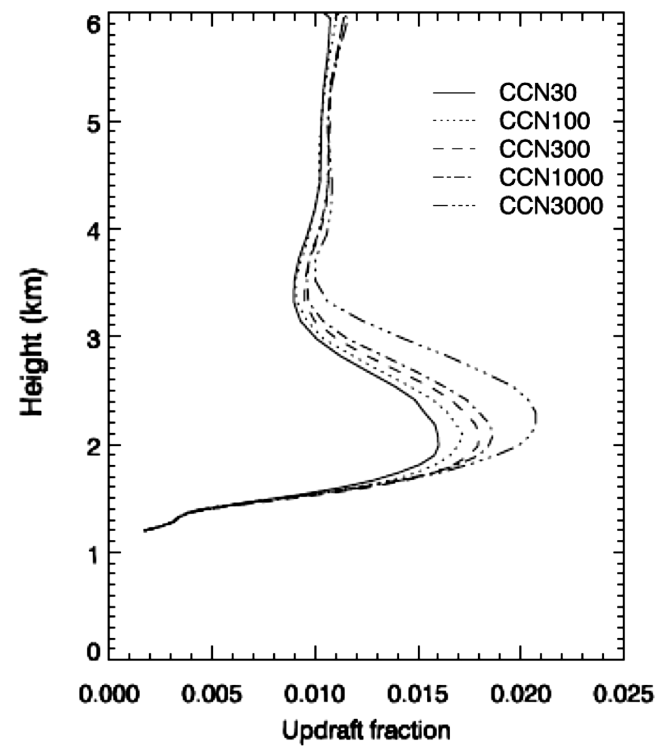

(b)

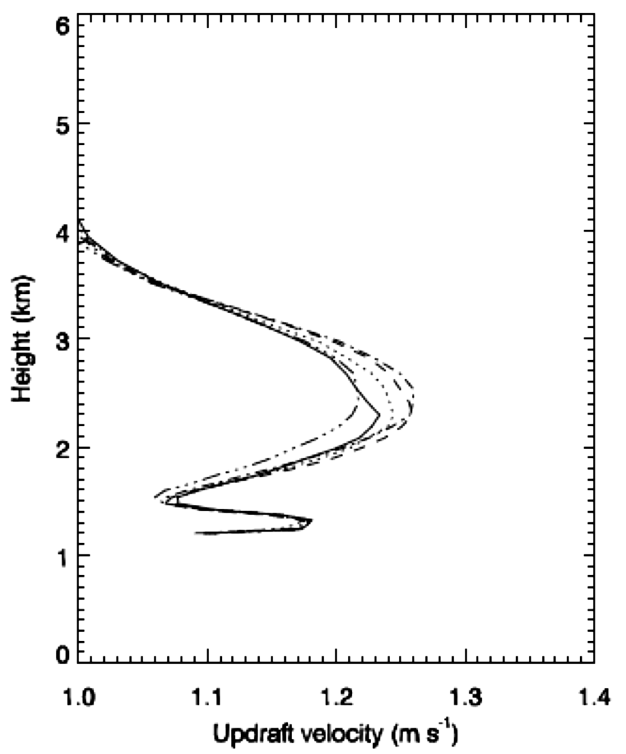

Figure 7. (a) The fraction of updraft grid points with vertical velocity larger than $1 \mathrm{~m} \mathrm{~s}^{-1}$ relative to the total domain grid points and (b) the mean updraft velocity for the grid points larger than $1 \mathrm{~m} \mathrm{~s}^{-1}$ over 14:00-16:00 UTC for the CMOC.
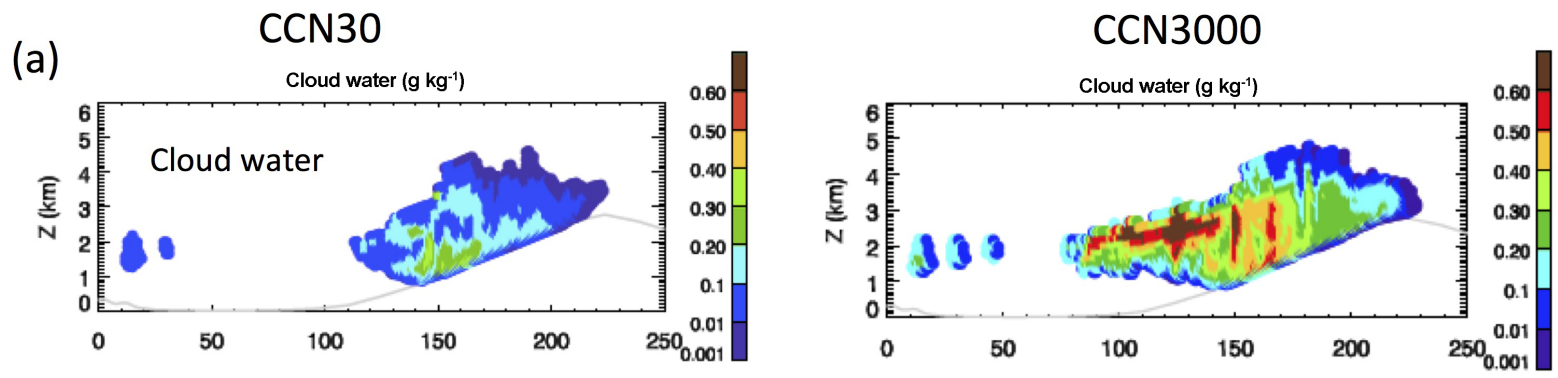

(b)
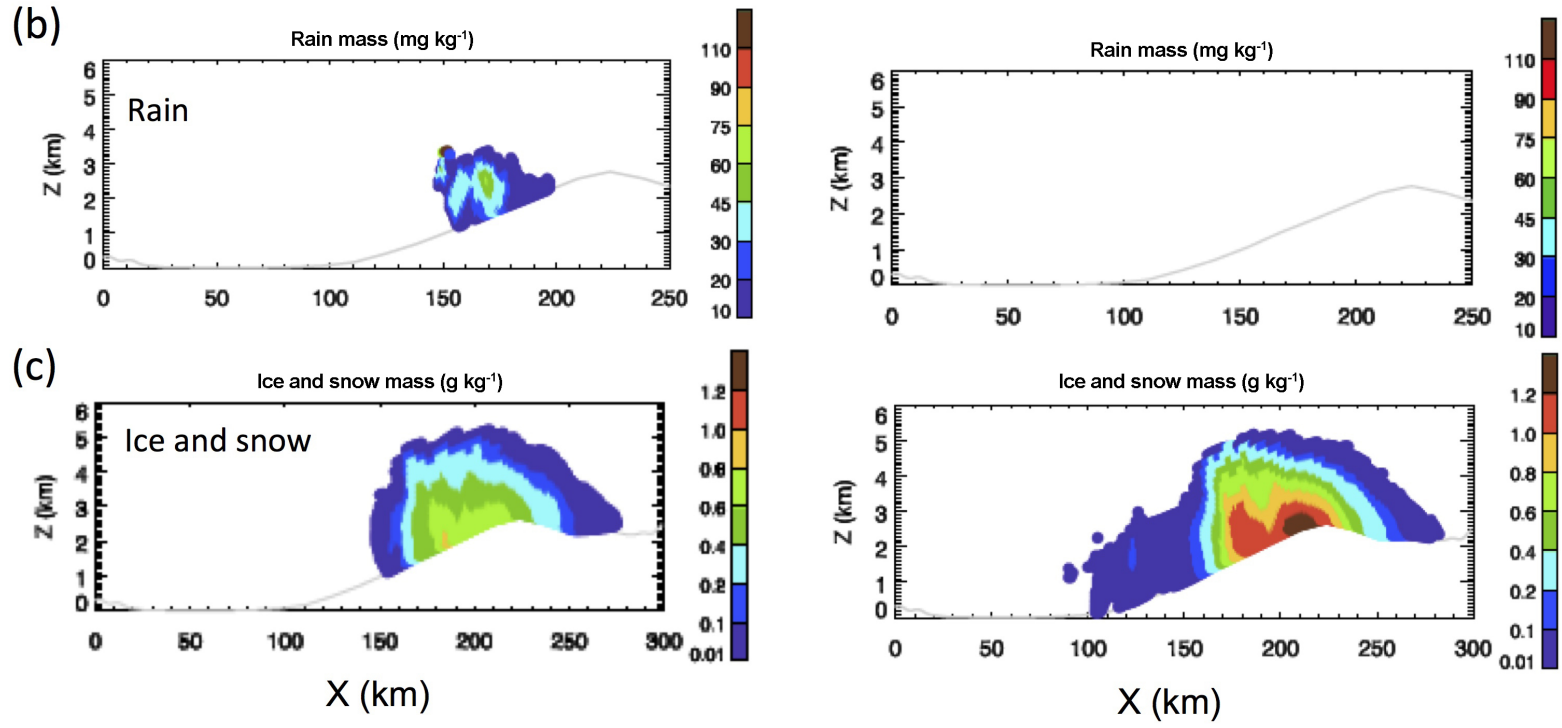

Figure 8. The west-east cross section of (a) cloud water content, (b) rain water content, and (c) ice and snow water content for CCN30 (left) and CCN3000 (right) with INP proxy concentrations of $1 \mathrm{~cm}^{-3}$ at 14:00 UTC averaged over the $20 \mathrm{~km}$ wide area zonally for the CMOC. 
(a)

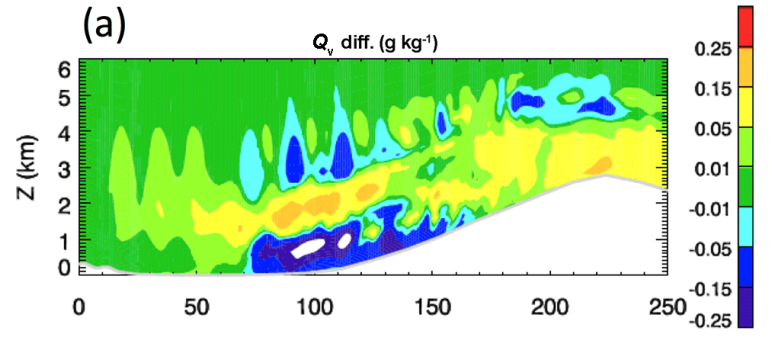

(b)

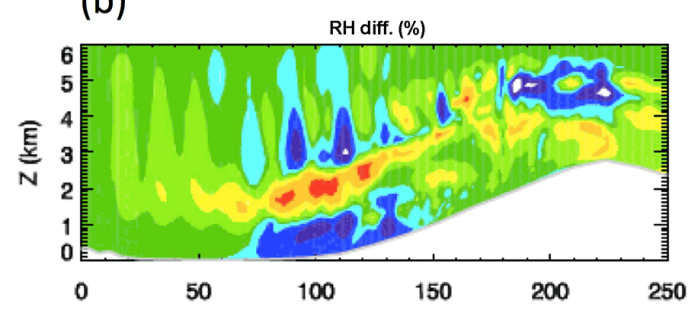

(c)

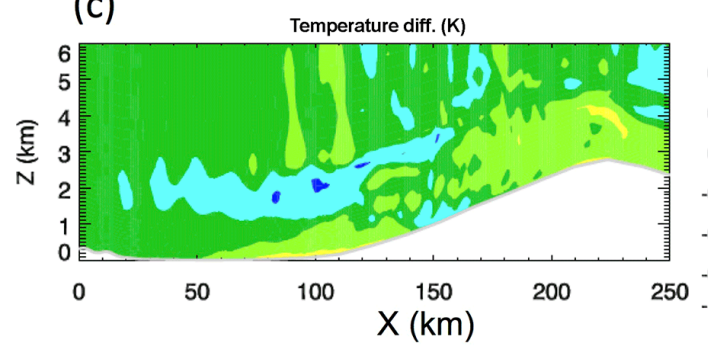

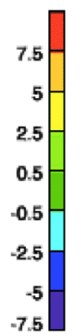

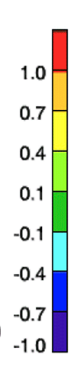

(d)

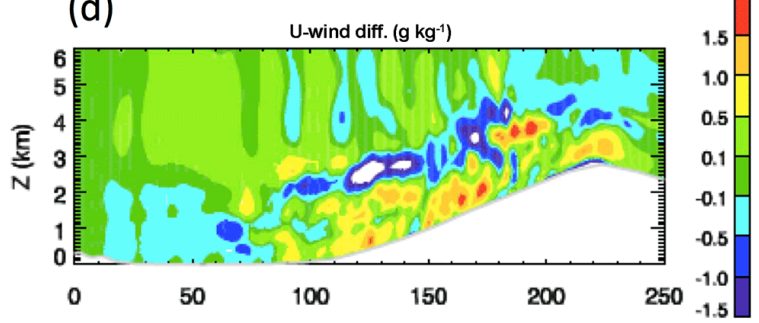

(e)
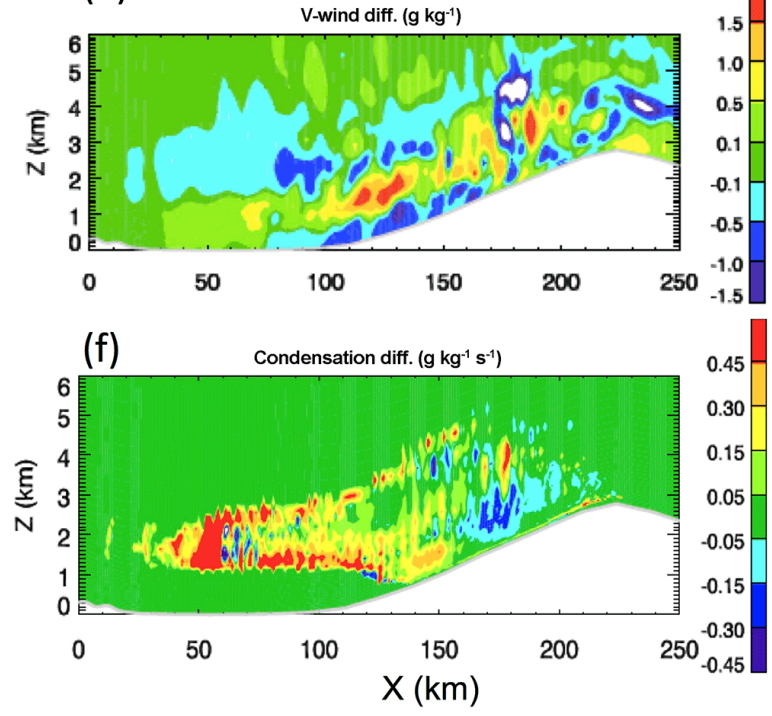

Figure 9. Differences in (a) water vapor, (b) $\mathrm{RH}$, (c) temperature, (d) $U$ component of the wind, (e) $V$ component of the wind, and (f) condensation rate between CCN3000 and CCN30 with an INP proxy concentration of $1 \mathrm{~cm}^{-3}$ for the CMOC. The cross section area is the same as Fig. 8. The time is at 14:00 UTC except that the condensation rate used for the difference calculation is the sum of that from 13:00 to 14:00 UTC to show an accumulated value over a $1 \mathrm{~h}$ period before 14:00 UTC.

vection occurs to form more clouds in the domain as $\mathrm{CCN}$ increase, especially in CCN3000. From the spatial distribution, we see that the increase in clouds is most prominent around the valley and foothills (i.e., the lower-part of the windward slope of the mountains). The cross sections of cloud water, rain, and ice-snow mass mixing ratios at 14:00 UTC clearly show that more clouds form over the valley and foothills in $\mathrm{CCN} 3000$, while in $\mathrm{CCN} 30$ there are fewer clouds over the valley and clouds are shallower over the valley and foothills (Fig. 8a). We see much more invigorated mixed-phase clouds in $\mathrm{CCN} 3000$ compared with CCN30. The mixed-phase clouds start from the foothills in CCN3000 (Fig. 8c), while CCN30 does not have the mixedphase clouds present until the regions above the middle and upper part of the mountain slope. This explains the increased ice nucleation rate in the domain at the lower altitudes, as shown in Fig. 6c.

The changes in cloud fields described above must involve dynamic and thermodynamic changes. By examining the differences of dynamic and thermodynamic fields between CCN3000 and CCN30 (Fig. 9), we clearly see that a band of increased water vapor and RH from the valley and/or foothills to the mountain at the higher altitudes (Fig. 9ab). The corresponding temperature is only slightly decreased (Fig. 9c), which should not affect the saturation water pressure and ice nucleation efficiency by much. Therefore, the increased RH is mainly caused by the increased water vapor, and this increase can be up to $8 \%$ in RH (e.g., from RH of 70 to $78 \%$ ). The large increase in $Q_{\mathrm{v}}$ and $\mathrm{RH}$ is mainly a result of changed local circulation, as shown in Fig. 9d-e: the wind blowing to the windward slope (zonal wind) gets stronger from CCN30 to CCN3000 (within $\sim 2 \mathrm{~km}$ above the ground) over the slope. In the case of atmospheric rivers, the stronger zonal wind transport means an increase in moisture transport to the mountains.

The changes in winds are only significant on the slope of the mountains and occur only after $2 \mathrm{~h}$ of the simulations (Fig. 10a), suggesting that they stem from more latent heat release as a result of more clouds over the valley and foothills (feedbacks of radiation and precipitation take a much longer time, especially considering the $2 \mathrm{~h}$ time, 04:00-06:00 LST). The clouds at the valley and/or foothill locations are generally shallow. Many literature studies, including both observations and model simulations, have shown that $\mathrm{CCN}$ en- 
(a) $\mathrm{CMOC}$

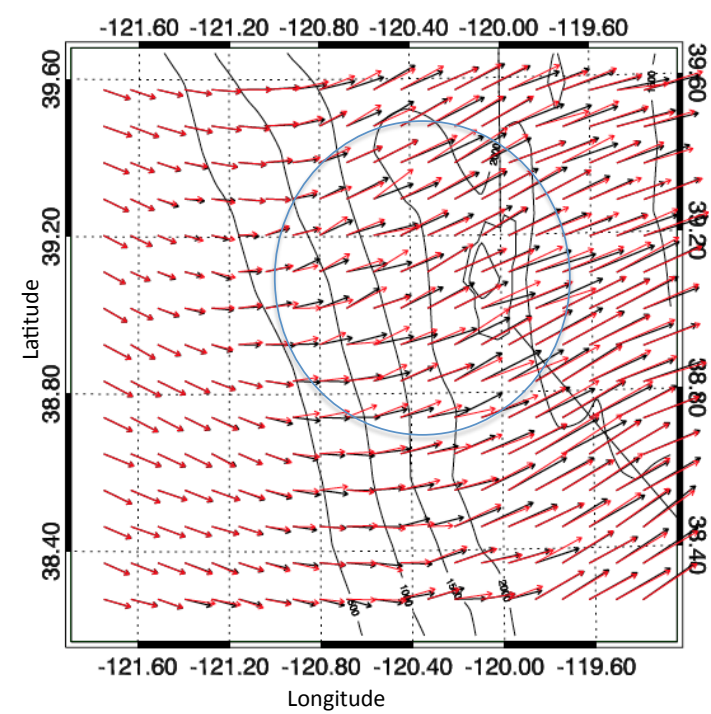

(b) WMOC

$$
\rightarrow 10 \mathrm{~m} \mathrm{~s}^{-1}
$$

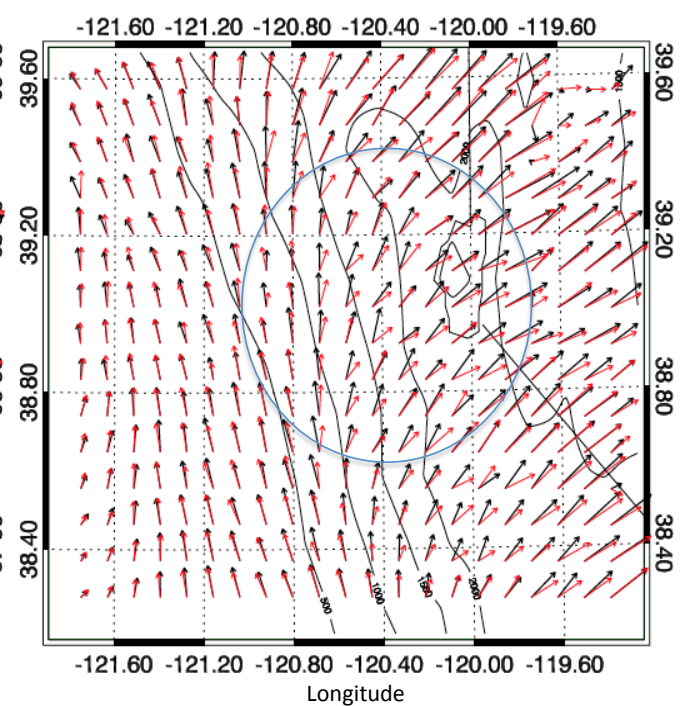

Figure 10. The spatial distribution of wind field at about $1.7 \mathrm{~km}$ above the ground for (a) the CMOC and (b) the WMOC at 14:00 UTC. Red denotes CCN3000 and black denotes CCN30 with IN1. The grey contour lines are the geophysical height in meters. The blue cycle is to mark the area with significant changes in wind (i.e., over the windward slope of the mountain).

(a)

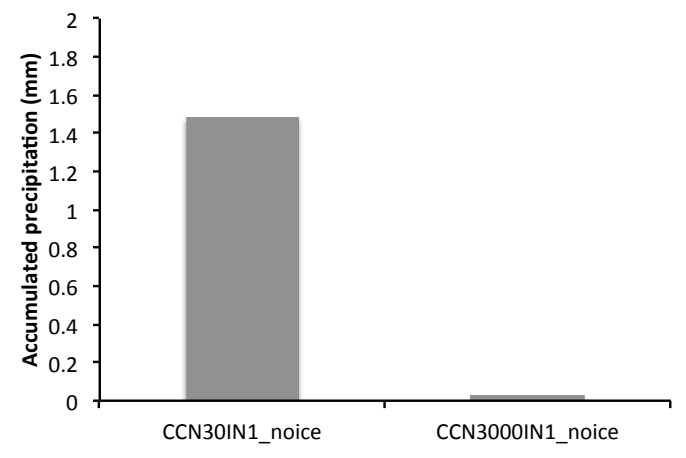

(b)

$\rightarrow 10 \mathrm{~m} \mathrm{~s}^{-1}$

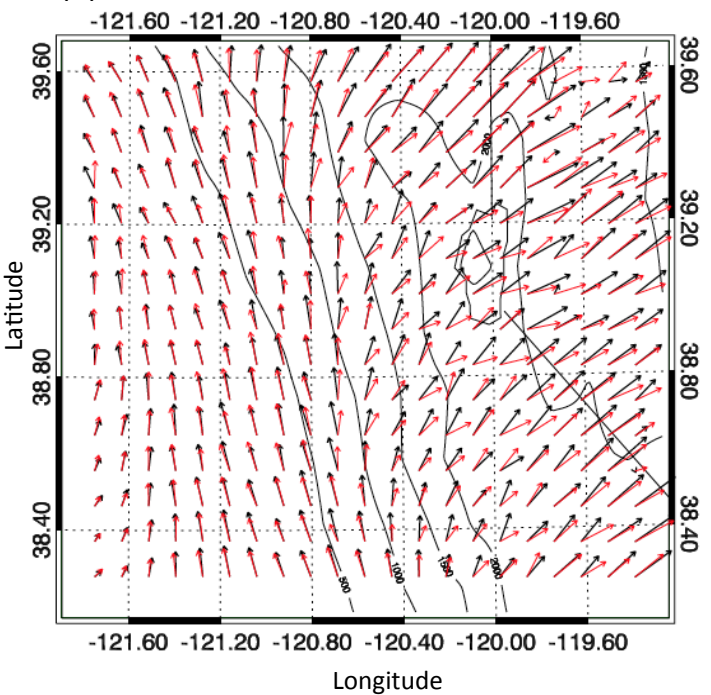

Figure 11. Results for the two simulations without ice-related microphysics, i.e., CCN30IN1_noice and CCN3000IN1_noice, which are based on CCN30IN1 and CCN3000IN1, respectively, for the WMOC: (a) the domain-averaged accumulated precipitation and (b) the spatial distribution of wind field at about $1.7 \mathrm{~km}$ above the ground at 14:00 UTC. Red in (b) denotes CCN3000IN1_noice and black denotes CCN30IN1_noice.

hance shallow cloud formation and deepen shallow clouds (e.g., Chen et al., 2015; Yuan et al., 2011; Pincus and Baker, 1994; Koren et al., 2014), which can be due to various reasons such as cloud lifetime effect, enhanced turbulent convection by larger entrainment rates as a result of stronger evaporation, and greater latent heat release due to larger drop surface area for stronger condensation. We find that condensation is indeed much enhanced over the valley and/or foothills from CCN30 to CCN3000 under IN1 (Fig. 9f), which results in much reduced supersaturation with respect to water (supersaturation around the cloud base in $\mathrm{CCN} 30$ at 13:00 UTC is about $0.28 \%$, while only $0.04 \%$ in CCN3000). 
The enhanced condensation as well as the cloud lifetime effect (i.e., conversion of smaller droplets into rain is slow and clouds can be sustained for a longer time) contributes to more shallow clouds in the valley or foothills. The more latent heat resulting from enhanced condensation leads to the change in local circulation, which transports more moisture to the windward slope of the mountain, resulting in more active mixed-phase clouds and snow precipitation through enhanced deposition and riming. In addition, over the mountains more supercooled liquid would be lifted to the higher altitudes in the polluted condition, forming ice and snow more efficiently through immersion freezing at the colder temperature, which contributes to more snow precipitation as well.

It should be noted that the mixed-phase clouds over the mountains are the key to the enhanced precipitation by $\mathrm{CCN}$. This is confirmed by sensitivity tests based on the WMOC case where ice-related microphysics were turned off in CCN30IN1 and CCN3000IN1. We chose the WMOC for this sensitivity test because the similar mechanism is present and the WMOC has less mixed-phase regime compared with the CMOC; thus, the factor would have a more significant role in the CMOC if it plays a role in the WMOC. As shown in Fig. 11a, precipitation is dramatically suppressed from CCN of 30 to $3000 \mathrm{~cm}^{-3}$ (Fig. 11a) and there is almost no precipitation in the valley and on the windward slope in CCN3000 due to extremely small droplets. However, we still see the change in the local circulation over the slope as a result of enhanced condensation (Fig. 11b). Therefore, the presence of ice is a necessary condition for such a large increase in precipitation by $\mathrm{CCN}$. Without ice processes (e.g., under the warm season with warm clouds only), precipitation over the mountains can not form efficiently in such polluted conditions even with the increased moisture. However, the added latent heat from condensation of vapor to water is still the main energy source of the invigoration.

In summary, increasing $\mathrm{CCN}$ forms more clouds in the valley and foothills (generally shallow) through much-enhanced condensation, which induces a local circulation change due to more latent heat release that enhances the zonal transport of moisture. This leads to the invigoration of the orographic mixed-phase clouds and drastically increased snow precipitation in this CMOC case. Therefore, aerosol impacts on orographic mixed-phase clouds can be extraordinary in extremely polluted conditions, especially under the influence of atmospheric rivers. In addition to the key role of ice processes for leading to greatly enhanced precipitation, orographic dynamics is another important factor since we do not see such impacts in the sensitivity tests where the terrain height is set to be $600 \mathrm{~m}$ for the locations with a terrain height $>600 \mathrm{~m}$ (precipitation becomes very small in those sensitivity tests and the increase from CCN30 to CCN3000 is small as well).

The increases of $Q_{\mathrm{v}}$ and RH are the most significant from CCN1000 to CCN3000 due to nonlinearity of aerosol-cloud interactions, explaining the large increase in snow precipita-
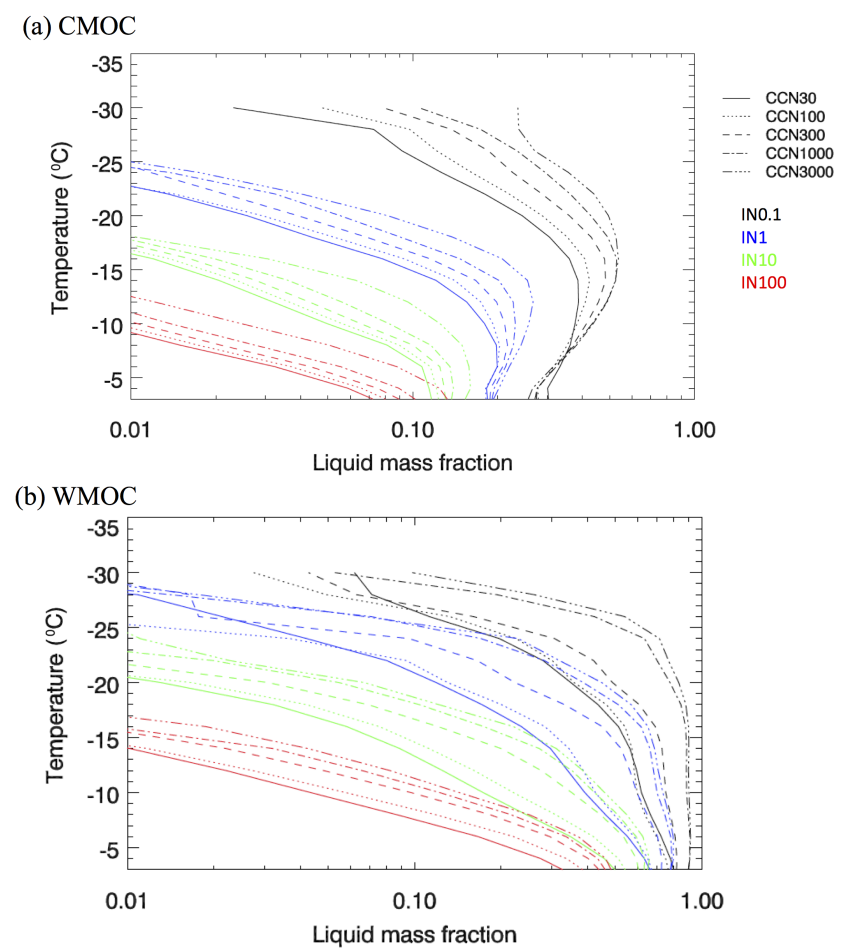

Figure 12. The liquid mass fraction vs. temperature for the (a) the CMOC and (b) the WMOC over the simulation time by excluding the first $2 \mathrm{~h}$. The liquid mass fraction is calculated for each temperature bin of a $2 \mathrm{~K}$ interval based on the total liquid water mixing ratio (droplets + raindrops) divided by the total condensate mixing ratio. The different line styles denote different $\mathrm{CCN}$ concentrations and different colors denote different INP concentrations.

tion. It is worth noting that in $\mathrm{CCN} 3000$, warm rain is completely shut off (left column in Fig. 8b); thus, much more cloud water can be transported to higher altitudes for more immersion freezing, which further enhances the snow precipitation. This likely contributes to the steep increase in precipitation when $\mathrm{CCN}$ reach $3000 \mathrm{~cm}^{-3}$.

\subsubsection{Supercooled water (SCW) content and cloud phase}

By changing the microphysical process rates, $\mathrm{CCN}$ and INP impact the cloud phases and SCW content. Figure 12 shows that INPs have the most striking impact on SCW. Increasing INPs enhance ice particle formation and then facilitate the deposition and riming processes in this CMOC case, as discussed in Sect. 3.1.1. The enhanced deposition in the WBF regime, along with riming, leads to a faster conversion of liquid to ice in the mixed-phase and glaciates the clouds faster. Therefore, SCW is substantially reduced as INPs increase (Fig. 12a). For example, in the case of CCN300, a significant amount of liquid mass fraction (0.1) exists at the temperature of $-30^{\circ} \mathrm{C}$ for the INO.1 case. Such a temperature is increased to -20 and $-10^{\circ} \mathrm{C}$ as dust-bio INP proxies are 
(a) $\mathrm{CMOC}$

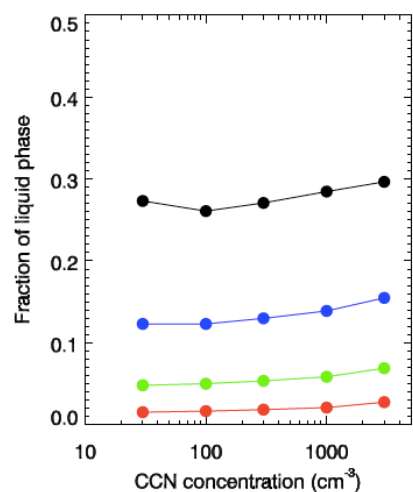

(b) WMOC

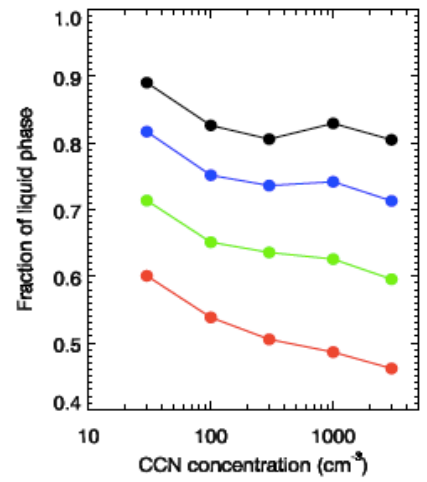

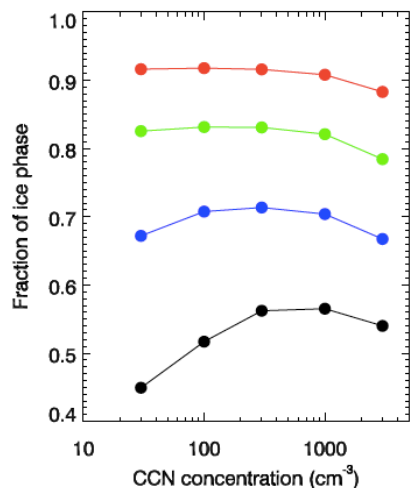
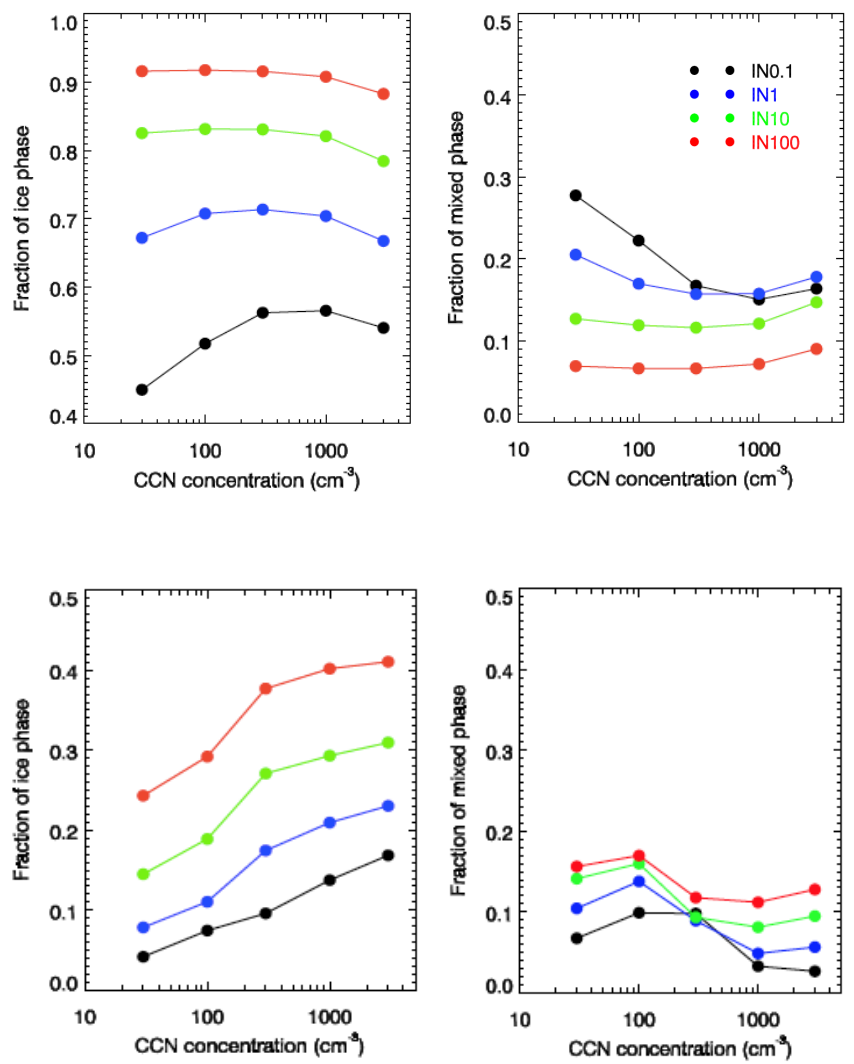

Figure 13. The fraction of the liquid phase (left), ice phase (middle), and mixed phase (right) for the (a) the CMOC and (b) the WMOC over the simulation period by excluding the first $2 \mathrm{~h}$. The cloud phase for each cloud grid point that has a total condensate mass of larger than $1 \times 10^{-5} \mathrm{~kg} \mathrm{~kg}^{-1}$ is identified based on the ratio of liquid to ice water mixing ratios. If the ratio is larger than 0.99 or smaller than 0.01 , the grid point is identified as liquid phase or ice phase, respectively. Between these values is identified as mixed phase. The fraction for each cloud phase is calculated by the number of grid points identified for the phase divided by the total number of the grid points of all three phases. Thus, the fractions of all three add up to 1 for each simulation case.

increased to 1 and $10 \mathrm{~cm}^{-3}$, respectively. In the extremely high INP case (INP100), there is nearly no supercooled water. As a result, the fractions of cloud phases are dramatically changed (Fig. 13a). As expected, higher INP concentrations decrease the fractions of liquid and mixed phases as the fraction of ice phase increases. In this CMOC case, the cloud phases are most sensitive to INPs at relatively low concentrations. For example, for the IN0.1-to-IN1 range that is likely common for this region in winter based on observations in the past field campaigns, the liquid phase fraction is reduced by nearly half and the ice phase fraction is 2 or more times as big (Fig. 13a). Note that the effects of INPs on cloud phase and SCW presented in this study may represent the upper limit because ice forms mainly through immersion freezing where large liquid particles transform to ice particles.

Compared with the effects of INPs, the magnitude of CCN effects on SCW and cloud phases is much smaller but still significant (the lines with the same color but different line styles in Fig. 12). Moreover, the sign is opposite. Increas- ing CCN generally increases SCW slightly (Fig. 12a). The impact of CCN on cloud phases is generally small, except when INPs are very low, i.e., IN0.1 (Fig. 13a). In this lowINP case, increasing CCN increases ice phase fractions and reduces the mixed-phase fraction when $\mathrm{CCN}$ are relatively low. This is because liquid clouds are dominant, making such clouds sensitive to the $\mathrm{CCN}$-enhanced ice nucleation as discussed in Sect. 3.1.2.

\subsection{WMOC - MARO2}

For this warm mixed-phase cloud case, the surface accumulated precipitation is suppressed by increasing $\mathrm{CCN}$ when $\mathrm{CCN}$ are lower than $1000 \mathrm{~cm}^{-3}$ (Fig. 14a), which is different from the case of the CMOC where the sign of $\mathrm{CCN}$ impact on precipitation depends on INP concentration. This is because the clouds in this WMOC behave similarly to warm clouds due to less efficient ice nucleation at the warm cloud temperatures. When $\mathrm{CCN}$ are lower than $1000 \mathrm{~cm}^{-3}$, the large decrease in warm rain (Fig. 14b) overpowers the slight changes 
(a)

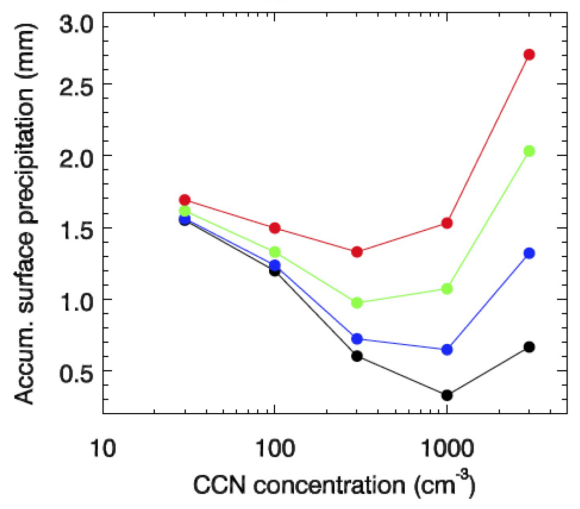

(b)

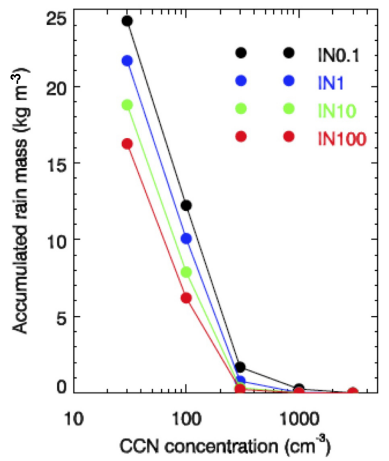

(c)

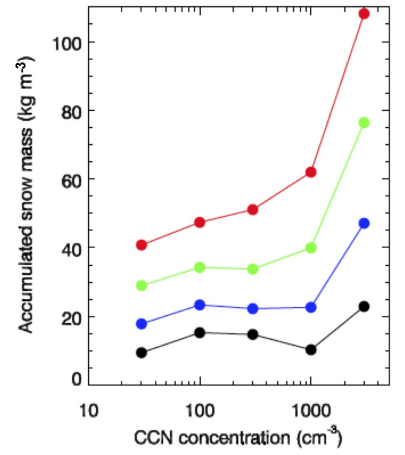

Figure 14. Same as Fig. 2, except for the WMOC.
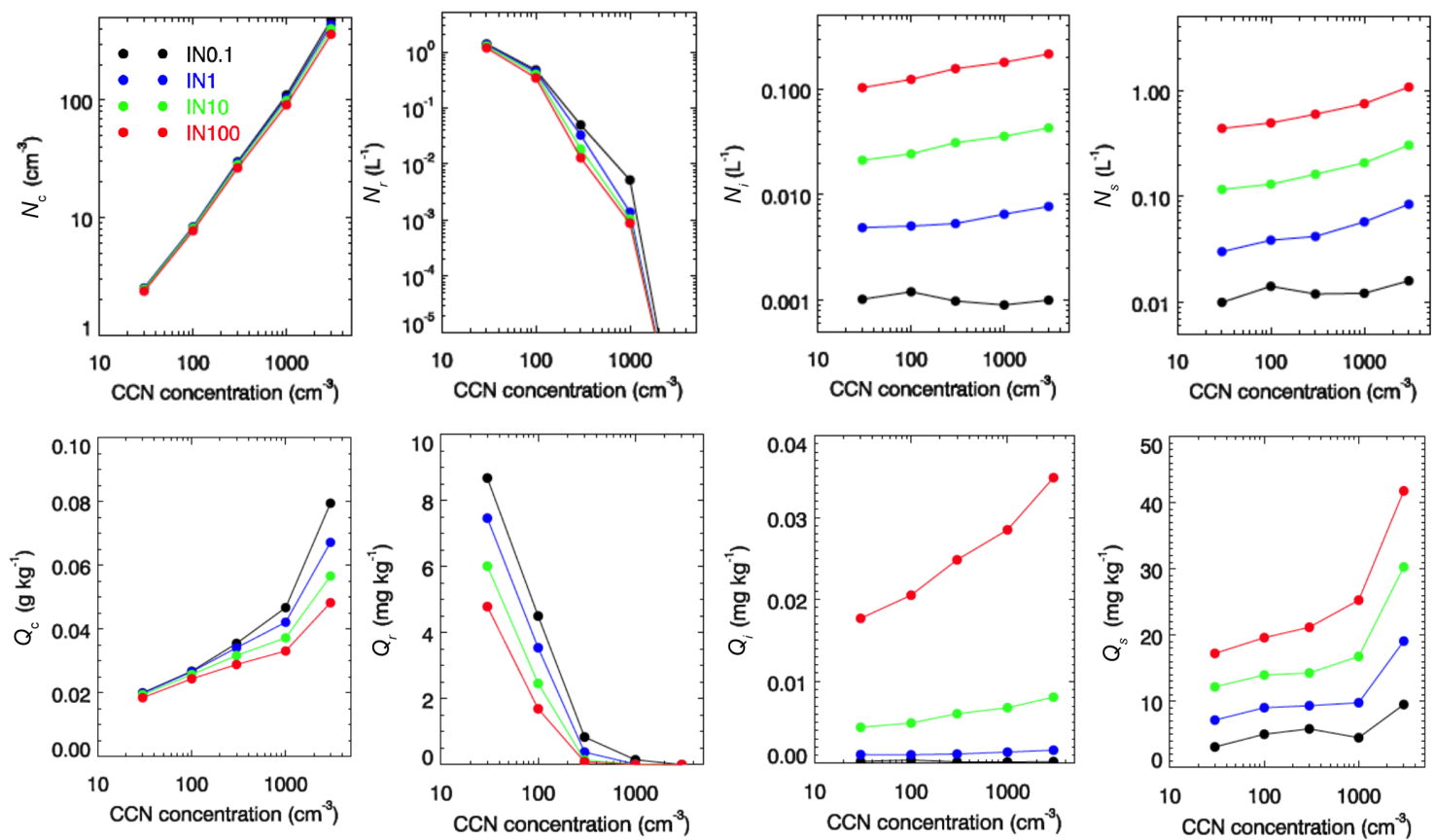

Figure 15. Same as Fig. 3, except for the WMOC.

in snow precipitation (Fig. 14c). Similar to the CMOC, we see a drastic increase in surface precipitation from CCN1000 to $\mathrm{CCN} 3000$, also due to a drastic increase in snow precipitation. Increasing INPs enhance surface precipitation in a more significant manner than in CMOC. In other words, the WMOC is more sensitive to INPs than the CMOC.

The in-cloud microphysical properties also show similar results to the CMOC: the steep increases of the snow mass and cloud water mixing ratios from $\mathrm{CCN} 1000$ to CCN3000 (Fig. 15). We have done the same investigation as in Sect. 3.1.1 and found that the mechanism causing the increased cloud water and snow production is similar to that in the $\mathrm{CMOC}$, that is, increasing $\mathrm{CCN}$ forms more shallow clouds in the large area of the valley and foothills, which sig- nificantly induces a change in local circulation through more latent heat release, which in turn increases the zonal transport of moisture to the windward slope of the mountains. Additionally, more abundant warm rain is present in the wide valley area in this case when $\mathrm{CCN}$ are low $\left(30 \mathrm{~cm}^{-3}\right)$, compared with the CMOC. The suppression of warm rain as CCN increase is very significant, as shown in Figs. $14 \mathrm{~b}$ and 15. Over the mountain, this suppression increases $Q_{\mathrm{c}}$ and allows more cloud water to be transported to the higher altitudes along the slope where immersion freezing is able to occur at lower temperatures. Ice multiplication through the Hallett-Mossop parameterization (Hallett and Mossop, 1974) in this WMOC contributes to ice particle concentration by $10-15 \%$ when $\mathrm{CCN}$ are $30 \mathrm{~cm}^{-3}$ and INP proxy aerosol concentrations are 
(a) Condensation

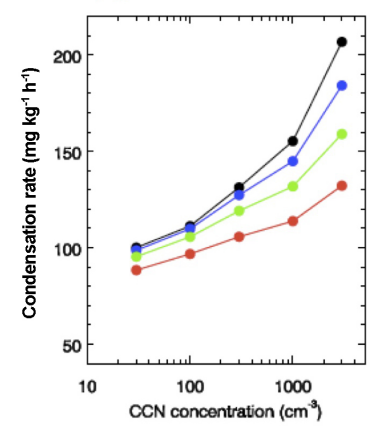

(c) Deposition

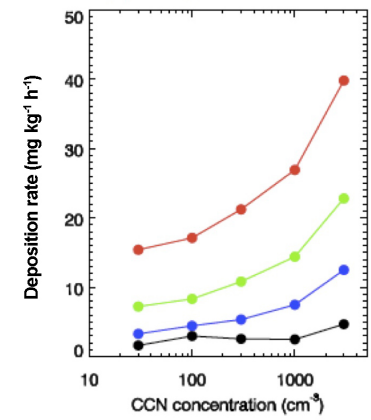

(e) Riming

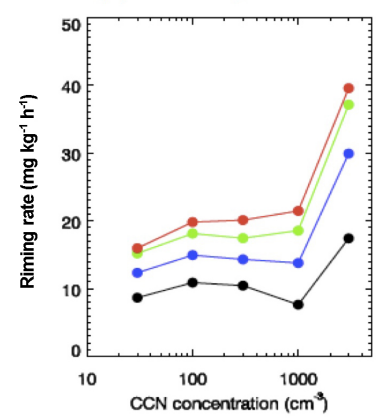

(b) Evaporation

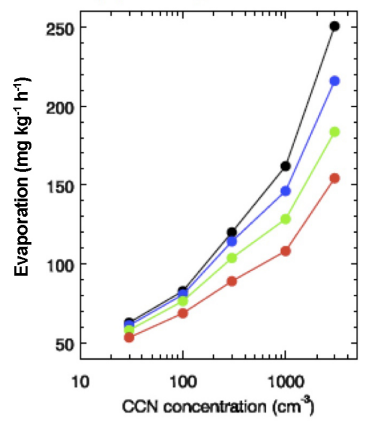

(d) Sublimation

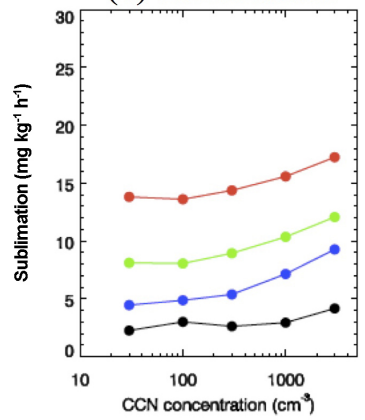

Different from the CMOC case, riming is a more efficient ice growth process for forming snow than deposition in this case, except when INP concentrations are extremely high (IN100) where both riming and deposition contribute at a similar magnitude (Fig. 16). In addition, the riming rate increases as INP concentrations increase, which is opposite to that of the CMOC. This is because the WMOC is ice-limited and there are not enough ice particles to collide with liquid particles when INP numbers are low; therefore, increasing the INPs boosts ice particles and allows more riming to occur. In contrast, the CMOC case is liquid-limited; thus, increasing the INPs reduces liquid particles available for riming due to ice depositional growth. We also see that condensation and evaporation rates are generally more than 2 times larger in this case compared with the CMOC, and both rates increase more significantly with $\mathrm{CCN}$ concentration in this WMOC. This is related to the dominance of liquid clouds in the WMOC. The more significant increase in condensation from increasing the $\mathrm{CCN}$ compared with the CMOC case is likely a result of the more significant change in the local circulation that is associated with a larger number of shallow clouds forming in the valley. Increasing the INP number concentrations reduces evaporation simply because of the reduction of liquid due to increased deposition and riming.

Similar to the CMOC, increasing CCN enhances the WBF process for this WMOC since more droplet evaporation and ice deposition occur (Fig. 17a and b). With the increase in $\mathrm{CCN}$, the domain-mean riming rate is not changed much until $\mathrm{CCN}$ of $1000 \mathrm{~cm}^{-3}$ (Fig. 16e), but the riming rate in the WBF regime increases (Fig. 17c), possibly due to larger ice particles resulting from stronger deposition growth in the WBF regime.

Results regarding the $\mathrm{CCN}$ and INP impact on supercooled water content in the WMOC case are similar to those in the CMOC case: increasing the INPs dramatically reduces SCW and increases cloud glaciation temperature, while increasing $\mathrm{CCN}$ has the opposite effect with much smaller significance (Fig. 12b). Compared with the CMOC, the effects of INPs on SCW are a little smaller but CCN effects are a little larger. The liquid-phase fraction (number fraction of cloudy grid points for which the liquid represents $99 \%$ or more of the condensate mass) decreases significantly as INPs increase (Fig. 13b). Correspondingly, the fractions of the mixed-phase and ice-phase cloud volumes increase due to increased ice nucleation. Similar to the increased riming as INPs increase, the mixed-phase fraction increases in the WMOC as well, which is opposite to the case for the CMOC, resulting from the ice-limited conditions in the WMOC versus the liquid-limited conditions in the CMOC. Note that INP effects are more significant at higher INP concentrations in this case, while in the CMOC the sensitivity decreases as INP increases, suggesting that the optimal INP concentration for the maximum INP impact is higher in warmer clouds than colder clouds because ice formation at warmer cloud temperatures is less efficient. The CCN impacts on cloud phase 
(a)

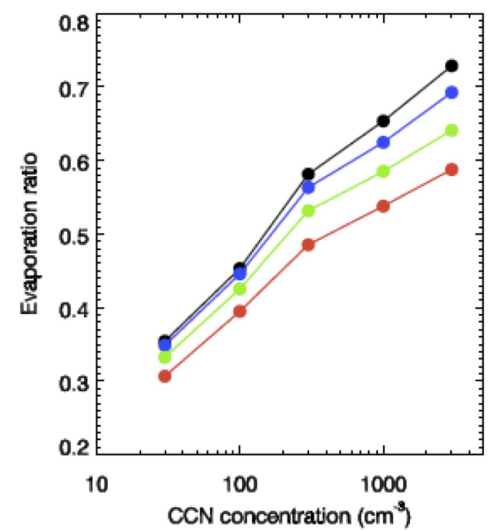

(b)

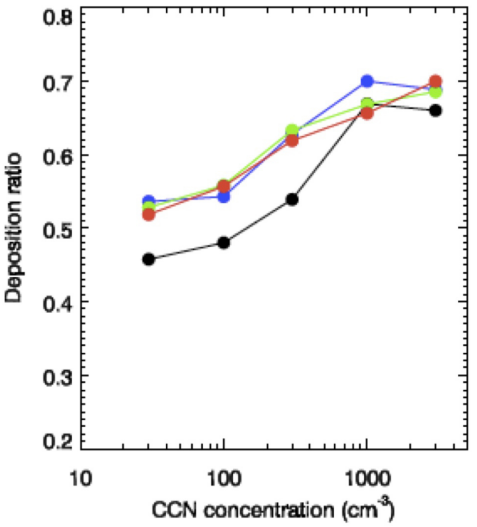

(c)

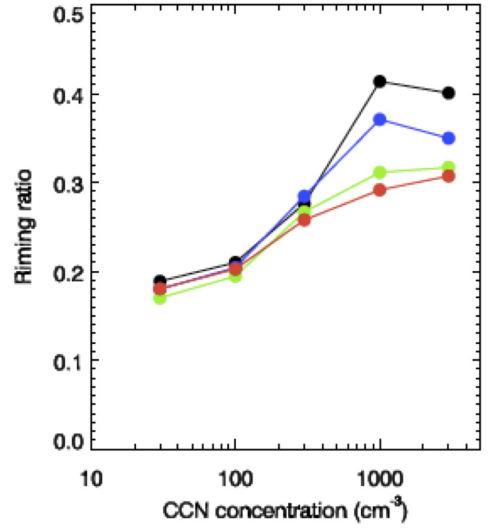

Figure 17. Same as Fig. 5, except for the WMOC.

are more significant in this WMOC compared with those in the CMOC. The decreased liquid cloud fraction with the increase in $\mathrm{CCN}$ is a consequence of the large increase in icephase fraction resulting from more active cold-cloud processes since the total cloud fraction sums up to 1 (Fig. 13b).

\section{Conclusions and discussion}

Extending the previous study of Fan et al. (2014), we conducted new simulations at a higher resolution and further sensitivity studies based on the same two cases of mixedphase orographic clouds forming on the Sierra Nevada barrier under the influence of atmospheric rivers during the CalWater 2011 field campaign to quantify the response of precipitation to changes in $\mathrm{CCN}$ and INPs and to examine $\mathrm{CCN}$ and INP impacts on SCW and cloud phases. The two mixedphase cloud cases have contrasting thermodynamics and dynamics: FEB16 has cold cloud temperatures and northwesterly wind flow at lower levels (i.e., the CMOC), while MAR02 has cloud temperatures that are about $10{ }^{\circ} \mathrm{C}$ warmer and southerly wind flow (i.e., the WMOC).

It is found that in the CMOC case deposition contributes more significantly to snow production than riming because deposition process is efficient at the cold cloud temperatures (from -22 to $-32^{\circ} \mathrm{C}$ ) in this case. In the WMOC, riming generally contributes more significantly because the deposition growth process is less efficient at the warmer temperatures (generally warmer than $-20^{\circ} \mathrm{C}$ in this case), except in the extremely high INP case where both riming and deposition contribute similarly.

We find that increasing the INP concentrations enhances snow precipitation on the windward slope of the Sierra Nevada in both the CMOC and WMOC cases. With the increase in INPs, the increased ice nucleation via immersion freezing enhances snow formation by intensifying depositional growth of ice in the CMOC, while both deposition and riming contribute in the WMOC. Increasing the INPs re- duces riming in the CMOC because of the liquid-limited condition in which more efficient depositional growth at higher INP number concentrations glaciates clouds and reduces liquid particles available for riming. However, in the ice-limited conditions of the WMOC, increasing the INPs boosts ice particle concentrations so that more riming can occur in a liquidrich condition. For the same reason, increasing the INPs suppresses the WBF processes due to reduced liquid particles.

The CCN impacts on precipitation are complicated, depending on cloud temperature and concentrations of $\mathrm{CCN}$ and INPs. When CCN are lower than $1000 \mathrm{~cm}^{-3}$, boosting $\mathrm{CCN}$ concentrations slightly increases snow precipitation, but the total precipitation can be increased or decreased depending on the INP concentrations in the CMOC. In contrast, in the WMOC, increasing $\mathrm{CCN}$ suppresses the total precipitation due to the large suppression of warm rain production. We find a drastic increase in snow precipitation by increasing $\mathrm{CCN}$ when $\mathrm{CCN}$ are high $\left(1000 \mathrm{~cm}^{-3}\right.$ or larger $)$ consistently in both the CMOC and the WMOC as a result of increased deposition and riming rates. The mechanism by which this occurs is through a larger number of shallow clouds that form in the wide valley area and foothills with increasing $\mathrm{CCN}$, which induces a change in local circulation through more latent heat release and increases the zonal transport of moisture to the windward slope of the mountains. This results in much more invigorated mixed-phase clouds with enhanced deposition and riming processes and therefore much more snow precipitation. Additionally, over the mountains the suppression of warm rain as CCN increase allows more cloud droplets to be transported to the higher altitudes where immersion freezing is able to occur efficiently, contributing to the enhanced snow as well. This effect is most significant when warm rain is completely shut off at $\mathrm{CCN}$ of $1000 \mathrm{~cm}^{-3}$ and higher. Note that this significant CCN impact on precipitation for $\mathrm{CCN}$ of $1000 \mathrm{~cm}^{-3}$ or larger was not seen in FAN2014, because the CCN concentrations prescribed in that study were smaller than $1000 \mathrm{~cm}^{-3}$. Another difference 
is that $\mathrm{CCN}$ are set to be uniform and increased uniformly over the model domain in this study, while in FAN2014 only the $\mathrm{CCN}$ over the Central Valley and coastal urban area were increased.

Increasing INP concentrations dramatically reduces supercooled water content and increases cloud glaciation temperature, while increasing $\mathrm{CCN}$ has the opposite effect but with much smaller significance. As expected, the fraction of liquid-phase clouds is decreased and the ice-phase fraction is increased by increasing the INPs in both cases. However, we see a decreased fraction of mixed-phase clouds from INP in the CMOC but increased in the WMOC, relating to the liquid-limited condition in the former where increasing ice formation enhances cloud glaciation. Conversely, in the icelimited condition in the latter, more liquid clouds are converted to mixed-phase clouds as INPs increase. Compared with the effects of INPs, the magnitude of CCN effects on SCW and cloud phases is much smaller and the signs are opposite. Increasing $\mathrm{CCN}$ generally enhances $\mathrm{SCW}$ in both cases. The relative fractions of cloud phases are not much impacted by $\mathrm{CCN}$ in the CMOC, except when INPs are very low (i.e., IN0.1). However, in the WMOC, increasing CCN evidently decreases liquid cloud fraction but increases ice-phase fraction. Thus, cloud phases in the WMOC have a large sensitivity to CCN compared with CMOC.

This study provides a better understanding of the $\mathrm{CCN}$ and INP effects on orographic mixed-phase cloud properties and precipitation. The result that high $\mathrm{CCN}$ dramatically increase snow precipitation over the mountains $\left(1000 \mathrm{~cm}^{-3}\right.$ or larger) as a result of modified cloud properties in the valley and foothills is different from previous modeling studies in the literature such as Lowenthal et al. (2011). There are many possibilities of what could lead to these differences, including different cloud cases and different model parameterizations, especially for riming processes. The mechanism for the drastic increase in the snow precipitation on the upwind slope from $\mathrm{CCN}$ in the very polluted conditions is new, and it suggests a strong impact from the shallow clouds in the valley and foothills on the mixed-phase clouds and precipitation over the mountains. It is worth noting that we do not see such significantly increased precipitation from $\mathrm{CCN}$ in the sensitivity tests without ice-related processes or without topography. This suggests that ice processes in the mixedphase clouds and orographically forced dynamics are the key factors for such CCN effects. Lynn et al. (2007) also showed that increasing the small aerosol particles led to an increased in-cloud snow mass content as a result of more ice particles being formed from droplet freezing due to suppressed warm rain formation and thereby more collisions between those ice particles. In contrast to our study, the total precipitation on the windward slope in Lynn et al. (2007) decreased since the snow particles had smaller size with lower fall speeds, and they were advected to the leeward side of the mountain, resulting in more precipitation there. A mechanism as in Lynn et al. (2007) was presented in Noppel et al. (2010), which showed a shift in precipitation from the Mediterranean sea to the land downwind by an increased number of small aerosols. This was because the delayed warm rain formation fostered the formation of extra ice particles with low settling velocity, which were then advected and enhanced precipitation inland. It should be noted that the primary ice nucleation mechanism implemented in the SBM for this study is based on observations and is totally different from those used in Lynn et al. (2007) and Noppel et al. (2010). This could lead to the different results of aerosol impact on precipitation over the windward slope in our study.

The mechanism leading to the enhanced precipitation over the windward slope by increasing $\mathrm{CCN}$ is seen in the two cases with very different cloud temperature, wind direction, and RH. However, the efficiency of the mechanism could depend on dynamics (wind speed) and thermodynamics (RH). As examined in Lynn et al. (2007), aerosol impact on orographic precipitation is reduced when RH is very high and increased as wind speed is reduced. Over the region of Sierra Nevada, CCN of above $1000 \mathrm{~cm}^{-3}$ would be an extreme condition. Therefore, this mechanism would not usually occur and the change in precipitation would not be much when $\mathrm{CCN}$ are less than $1000 \mathrm{~cm}^{-3}$, as shown in Figs. 2a and 14a in the normal conditions over this region. We show a precipitation suppression by $\mathrm{CCN}$ in the relatively warm situations, which is in agreement with the observations of Rosenfeld and Givati (2006). However, for many polluted regions such as China and India where $\mathrm{CCN}$ of above $1000 \mathrm{~cm}^{-3}$ are quite common, this mechanism may have very important implications for orographic precipitation extremes and water cycles.

It should be noted that our results for CCN and INP impacts on precipitation and supercooled water content may represent an upper limit since the major ice nucleation in the simulations is through immersion freezing that converts the largest liquid drops into ice or snow directly when ice nucleation occurs. This leads to very efficient conversion of liquid to ice and/or snow and then strong ice growth processes to form snow.

In our study, we do not see significant spillover effect of snowfall (i.e., decrease on the windward slope and increase on the leeward side slope by increasing $\mathrm{CCN}$ ) as found in Lynn et al. (2007) and Saleeby et al. (2011). Precipitation mainly forms on the windward slope of the Sierra Nevada and the increase in the snow precipitation is more significant on the windward slope than on the leeward side in both cases. The differing results between our study and Saleeby et al. (2011) could be related to different locations of the clouds over the mountain and/or different mountain topography or the presence of a low-level barrier jet in the atmospheric river environment that reduces the cross barrier flow. 


\section{Data availability}

All the model simulation data in this paper are deposited in the PNNL Institutional Computing resources and can be accessed by contacting jiwen.fan@pnnl.gov.

Acknowledgement. This study was supported by the California Energy Commission (CEC) and the Office of Science of the US Department of Energy as part of the Regional and Global Climate Modeling program. PNNL is operated for DOE by Battelle Memorial Institute under Contract DE-AC06-76RLO1830. Paul DeMott additionally acknowledges partial support from the US Department of Energy's Atmospheric System Research, an Office of Science, Office of Biological and Environmental Research program, under Grant no. DE-SC0014354.

Edited by: R. Krejci

Reviewed by: A. Khain and two anonymous referees

\section{References}

Ault, A. P., Williams, C. R., White, A. B., Neiman, P. J., Creamean, J. M., Gaston, C. J., Ralph, F. M., and Prather, K. A.: Detection of Asian dust in California orographic precipitation, J. Geophys. Res., 116, D16205, doi:10.1029/2010JD015351, 2011.

Bao, J.-W., Michelson, S. A., Neiman, P. J., Ralph, F. M., and Wilczak, J. M.: Interpretation of enhanced integrated water vapor bands associated with extratropical cyclones: Their formation and connection to tropical moisture, Mon. Weather Rev., 134, 1063-1080, doi:10.1175/MWR3123.1, 2006.

Bigg, E. K.: The formation of atmospheric ice crystals by the freezing of droplets, Q. J. Roy. Meteor. Soc., 79, 510-519, doi:10.1002/qj.49707934207, 1953.

Chen, Y.-C., Christensen, M. W., Diner, D. J., and Garay, M. J.: Aerosol-cloud interactions in ship tracks using Terra MODIS/MISR, J. Geophys. Res., 120, 2819-2833, doi:10.1002/2014jd022736, 2015.

Cotton, W., Tripoli, G., Rauber, R., and Mulvihill, E.: Numerical simulation of the effects of varying ice crystal nucleation rates and aggregation processes on orographic snowfall, J. Clim. Appl. Meteorol., 25, 1658-1680, 1986.

Creamean, J. M., Suski, K. J., Rosenfeld, D., Cazorla, A., DeMott, P. J., Sullivan, R. C., White, A. B., Ralph F. M., Minnis P., Comstock, J. M., Tomlinson, J, M., and Prather, K. A.: Dust and Biological Aerosols from the Sahara and Asia Influence Precipitation in the Western US, Science, 339, 1572-1578, doi:10.1126/science.1227279, 2013.

Creamean, J. M., Lee, C., Hill, T. C., Ault, A. P., DeMott, P. J., White, A. B., Ralph, F. M., and Prather, K. A.: Chemical properties of insoluble precipitation residue particles, J. Aerosol. Sci., 76, 13-27, 2014.

Creamean, J. M., Ault, A. P., White, A. B., Neiman, P. J., Ralph, F. M., Minnis, P., and Prather, K. A.: Impact of interannual variations in sources of insoluble aerosol species on orographic precipitation over California's central Sierra Nevada, Atmos. Chem. Phys., 15, 6535-6548, doi:10.5194/acp-15-6535-2015, 2015.
DeMott, P. J., Prenni, A. J., McMeeking, G. R., Sullivan, R. C., Petters, M. D., Tobo, Y., Niemand, M., Möhler, O., Snider, J. R., Wang, Z., and Kreidenweis, S. M.: Integrating laboratory and field data to quantify the immersion freezing ice nucleation activity of mineral dust particles, Atmos. Chem. Phys., 15, 393-409, doi:10.5194/acp-15-393-2015, 2015.

DeMott, P. J., Hill, T. C. J., McCluskey, C. S., Prather, K. A., Collins, D. B., Sullivan, R. C., Ruppel, M. J., Mason, R. H., Irish, V. E., Lee, T., Hwang, C. Y., Rhee, T. S., Snider, J. R., McMeeking, G. R., Dhaniyala, S., Lewis, E. R., Wentzell, J. J. B., Abbatt, J., Lee, C., Sultana, C. M., Ault, A. P., Axson, J. L., Diaz Martinez, M., Venero, I., Santos-Figueroa, G., Stokes, M. D., Deane, G. B., Mayol-Bracero, O. L., Grassian, V. H., Bertram, T. H., Bertram, A. K., Moffett, B. F., and Franc, G. D.: Sea spray aerosol as a unique source of ice nucleating particles, P. Natl. Acad. Sci. USA, 113, 5797-5803, doi:10.1073/pnas.1514034112, 2016.

Fan, J., Zhang, R., Li, G., and Tao, W.-K.: Effects of aerosols and relative humidity on cumulus clouds, J. Geophys. Res., 112, D14204, doi:10.1029/2006JD008136, 2007.

Fan, J., Ovtchinnikov, M., Comstock, J., McFarlane, S. A., and Khain, A.: Ice Formation in Arctic Mixed-Phase Clouds - Insights from a 3-D Cloud-Resolving Model with Size-Resolved Aerosol and Cloud Microphysics, J. Geophys. Res., 114, D04205, doi:10.1029/2008JD010782, 2009.

Fan, J., Leung, L. R., Li, Z., Morrison, H., Chen, H., Zhou, Y., Qian, Y., and Wang, Y.: Aerosol impacts on clouds and precipitation in eastern China: Results from bin and bulk microphysics, J. Geophys. Res., 117, D00K36, doi:10.1029/2011JD016537, 2012.

Fan, J., Leung, L. R., DeMott, P. J., Comstock, J. M., Singh, B., Rosenfeld, D., Tomlinson, J. M., White, A., Prather, K. A., Minnis, P., Ayers, J. K., and Min, Q.: Aerosol impacts on California winter clouds and precipitation during CalWater 2011: local pollution versus long-range transported dust, Atmos. Chem. Phys., 14, 81-101, doi:10.5194/acp-14-81-2014, 2014.

Fridlind, A. M., Ackerman, A. S., McFarquhar, G., Zhang, G., Poellot, M. R., DeMott, P. J., Prenni, A. J., and Heymsfield, A. J.:, Ice properties of single-layer stratocumulus during the MixedPhase Arctic Cloud Experiment: 2. Model results, J. Geophys. Res., 112, D24202, doi:10.1029/2007JD008646, 2007.

Hallett, J. and Mossop, S. C.: Production of secondary ice particles during the riming process, Nature, 249, 26-28, 1974.

Ilotoviz E., Khain, A. P., Benmoshe, N., Phillips, V. T. J., and Ryzhkov, A.V.: Effect of Aerosols on Freezing Drops, Hail, and Precipitation in a Midlatitude Storm, J. Atmos. Sci., 73, 109-144, 2016.

Jirak, I. L. and Cotton, W. R.: Effect of air pollution on precipitation along the Front Range of the Rocky Mountains, J. Appl. Meteorol. Clim., 45, 236-245, 2006.

Kay, J. E., Bourdages, L., Miller, N. B., Morrison, A., Yettella, V., Chepfer, H., and Eaton B.: Evaluating and improving cloud phase in the Community Atmosphere Model version 5 using spaceborne lidar observations, J. Geophys. Res.-Atmos., 121, 41624176, doi:10.1002/2015JD024699, 2016.

Khain, A. P., Pokrovsky, A., Pinsky, M., Seifert, A., and Phillips, V.: Simulation of effects of atmospheric aerosols on deep turbulent convective clouds using a spectral microphysics mixed-phase cumulus cloud model, Part I: Model description and possible applications, J. Atmos. Sci., 61, 2963-2982, 2004. 
Khain, A., Leung. L. R., Lynn, B., and Ghan, S.: Effects of aerosols on the dynamics and microphysics of squall lines simulated by spectral bin and bulk parameterization schemes, J. Geophys. Res., 114, D22203, doi:10.1029/2009JD011902, 2009.

Koren, I., Dagan G., and Altaratz O.: From aerosol-limited to invigoration of warm convective clouds, Science, 344, 1143-1146, doi:10.1126/science.1252595, 2014.

Li, G., Wang, Y., and Zhang, R.: Implementation of a twomoment bulk microphysics scheme to the WRF model to investigate aerosol-cloud interaction, J. Geophys. Res., 113, D15211, doi:10.1029/2007JD009361, 2008.

Lowenthal, D. H., Borys, R. D., Cotton, W., Saleeby, S., Cohn, S. A., and Brown, W. O. J.: The altitude of snow growth by riming and vapor deposition in mixed-phase orographic clouds, Atmos. Environ., 45, 519-522, doi:10.1016/j.atmosenv.2010.09.061, 2011.

Lynn, B., Khain, A., Rosenfeld, D., and Woodley, W. L.: Effects of aerosols on precipitation from orographic clouds, J. Geophys. Res., 112, D10225, doi:10.1029/2006JD007537, 2007.

Marwitz, J. D.: Deep Orographic Storms over the Sierra Nevada. Part II: The Precipitation Processes, J. Atmos. Sci., 44, 174-185, 1987.

Meyers, M. P., DeMott, P. J., and Cotton, W. R.: New primary icenucleation parameterizations in an explicit cloud model, J. Appl. Meteor., 31, 708-721, 1992.

Muhlbauer, A. and Lohmann, U.: Sensitivity studies of aerosol cloud interactions in mixed-phase orographic precipitation, J. Atmos. Sci., 66, 2517-2538, doi:10.1175/2009JAS3001.1, 2009.

Neiman, P. J., Sukovich, E. M., Ralph, F. M., and Hughes, M.: A Seven-Year Wind Profiler-Based Climatology of the Windward Barrier Jet along California's Northern Sierra Nevada, Mon. Weather Rev., 138, 1206-1233, 2010.

Noppel, H., Pokrovsky, A., Lynn, B., Khain, A. P., and Beheng, K. D.: On precipitation enhancement due to a spatial shift of precipitation caused by introducing small aerosols: numerical modeling, J. Geophys. Res., 115, D18212, doi:10.1029/2009JD012645, 2010.

Pincus, R. and Baker, M. B.: Effect of Precipitation on the Albedo Susceptibility of Clouds in the Marine Boundary-Layer, Nature, 372, 250-252, doi:10.1038/372250a0, 1994.

Ralph, F. M., Neiman, P. J., Kiladis, G. N., Weickman, K., and Reynolds, D. W.: A multi-scale observational case study of a Pacific atmospheric river exhibiting tropical-extratropical connections and a mesoscale frontal wave, Mon. Weather Rev., 139, 1169-1189, doi:10.1175/2010MWR3596.1, 2011.

Ralph, F. M., Prather, K. A., Cayan, D., Spackman, J. R., DeMott, P., Dettinger, M., Fairall, C., Leung, R., Rosenfeld, D., Rutledge, S., Waliser, D., White, A. B., Cordeira, J., Martin, A., Helly, J., and Intrieri, J.: Calwater Field Studies Designed to Quantify the Roles of Atmospheric Rivers and Aerosols in Modulating Us West Coast Precipitation in a Changing Climate, B. Am. Meteorol. Soc., 97, 1209-1228, 2016.

Rauber, R.: Microphysical Structure and Evolution of a Central Sierra Nevada Orographic Cloud System, J. Appl. Meteorol., 32, 3-24, 1992.

Rosenfeld, D. and Givati, A.: Evidence of orographic precipitation suppression by air pollution-induced aerosols in the western United States, J. Appl. Meteorol. Clim., 45, 893-911, doi:10.1175/JAM2380.1, 2006.
Rosenfeld, D., Lohmann, U., Raga, G. B., O’Dowd, C. D., Kulmala, M., Fuzzi, S., Reissell, A., and Andreae, M. O.: Flood or drought: How do aerosols affect precipitation?, Science, 321, 1309-1313, doi:10.1126/science.1160606, 2008.

Rosenfeld, D., Yu, X., Liu, G., Xu, X., Zhu, Y., Yue, Z., Dai, J., Dong, Z., Dong, Y., and Peng, Y.: Glaciation temperatures of convective clouds ingesting desert dust, air pollution and smoke from forest fires, Geophys. Res. Lett., 38, L21804, doi:10.1029/2011GL049423, 2011.

Rosenfeld, D., Rei, Chemke, DeMott, P., Sullivan, R. C., Rasmussen, R., McDonough, F., Comstock, J., Schmid, B., Tomlinson, J., Jonsson, H., Suski, K., Cazorla, A., and Prather, K., The common occurrence of highly supercooled drizzle and rain near the coastal regions of the western United States, J. Geophys. Res.-Atmos., 118, 9819-9833, doi:10.1002/jgrd.50529, 2013.

Rosenfeld, D., Chemke, R., Prather, K., Suski, K., Comstock, J. M., Schmid, B., Tomlinson, J., and Jonsson, H.: Polluting of winter convective clouds upon transition from ocean inland over central California: Contrasting case studies, Atmos. Res., 135, 112-127, 2014.

Saleeby, S. M., Cotton, W. R., and Fuller, J. D.: The Cumulative Impact of Cloud Droplet Nucleating Aerosols on Orographic Snowfall in Colorado, J. Appl. Meteorol. Clim., 50, 604-625, 2011.

Saleeby, S. M., Cotton, W. R., Lowenthal, D., and Messina, J.: Aerosol Impacts on the Microphysical Growth Processes of Orographic Snowfall, J. Appl. Meteorol. Clim., 52, 834-850, 2013.

Shen, X., Wang, Y., Zhang, N., and Li, X.: Precipitation and cloud statistics in the deep tropical convective regime, J. Geophys. Res., 115, D24205, doi:10.1029/2010JD014481, 2010.

Skamarock, W. C., Klemp, J. B., Dudhia J., Gill, D. O., Barker, D. M., Huang, X.-Y., Wang, W., and Powers, J. G.: A description of the Advanced Research WRF version 3. NCAR Tech, Note NCAR/TN-475+STR, 113 pp., 2008.

Tao, W.-K., Chen, J.-P., Li, Z., Wang, C., and Zhang, C.: Impact of aerosols on convective clouds and precipitation, Rev. Geophys., 50, RG2001, doi:10.1029/2011RG000369, 2012.

Uno, I., Eguchi, K., Yumimoto, K., Takemura, T., Shimizu, A., Uematsu, M., Liu, Z., Wang, Z., Hara, Y., and Sugimoto, N.: Asian dust transported one full circuit around the globe, Nat. Geosci., 2, 557-560, doi:10.1038/ngeo583, 2009.

Xiao, H., Yin, Y., Jin, L., Chen, Q., and Chen, J.: Simulation of the effects of aerosol on mixed-phase orographic clouds using the WRF model with a detailed bin microphysics scheme, J. Geophys. Res.-Atmos., 120, 8345-8358, doi:10.1002/2014JD022988, 2015.

Young, K. C.: A numerical simulation of wintertime, orographic precipitation, Part I: Description of model microphysics and numerical techniques, J. Atmos. Sci., 31, 1735-1748, 1974.

Yuan, T., Remer, L. A., and Yu, H.: Microphysical, macrophysical and radiative signatures of volcanic aerosols in trade wind cumulus observed by the A-Train, Atmos. Chem. Phys., 11, 71197132, doi:10.5194/acp-11-7119-2011, 2011.

Zipori, A., Rosenfeld, D., Tirosh, O., Teutsch, N., and Erel, Y.: Effects of aerosol sources and chemical compositions on cloud drop sizes and glaciation temperatures, J. Geophys. Res.-Atmos., 120, 9653-9669, doi:10.1002/2015JD023270, 2015. 